University of Rhode Island

DigitalCommons@URI

Open Access Dissertations

1970

\title{
The Solubility of Amino Acids in Various Solvent Systems
}

Thomas E. Needham

University of Rhode Island

Follow this and additional works at: https://digitalcommons.uri.edu/oa_diss

\section{Recommended Citation}

Needham, Thomas E., "The Solubility of Amino Acids in Various Solvent Systems" (1970). Open Access Dissertations. Paper 159.

https://digitalcommons.uri.edu/oa_diss/159

This Dissertation is brought to you for free and open access by DigitalCommons@URI. It has been accepted for inclusion in Open Access Dissertations by an authorized administrator of DigitalCommons@URI. For more information, please contact digitalcommons-group@uri.edu. 
THE SOLUBILITY OF AMINO ACIDS

$\underline{\text { IN }}$

VARIOUS SOLVENT SYSTEMS

BY

THOMAS E. NEEDHAM, JR.

A THESIS SUBMITTED IN PARTIAL FULFILLMENT OF THE REQUIREMENTS FOR THE DEGREE OF DOCTOR OF PHILOSOPHY

IN

PHARMACEUTICA L SCIENCES

UNIVERSITY OF RHODE ISLAND 
TITLE ABSTRACT

SOLUBILITY OF AMINO ACIDS 


\section{ABSTRACT}

The effect of varying solvent systems on the solubilities of glycine, L-alanine, L-valine, L-phenylalanine, and DL-aminooctanoic acid at $25^{\circ} \mathrm{C}$. was studied. The entire concentration spectrum from pure water to pure semipolar solvent was used for each of the solvent systems of methanol-water, ethanol-water, n-propanolwater, isopropanol-water,, and tertiary butanol-water. Further, the effect of $\mathrm{pH}$ variation on the solubilities of the amino acids in each of the solvent systems was studied. Aliquots were withdrawn from each solvent system studied and analyzed gravimetrically to determine the resultant solubility. It was found that the solubility. behavior of those amino acids studied was a function of the constant effect of the -amino carboxylic acid portion of the molecule and the independent interactions of the remaining neutral portion of the molecule. Maximum solubility was found in pure water with a reduction to low solubility in the semipolar solvents in the order of a second degree polynomial equation. To each percent strength of the hydroalcoholic solvent systems, the ratio of water to alcoholic molecules per amino acid molecule remains constant. This would indicate that the lengthening of the nonpolar portion of the chain from the hydrogen of glycine to the methyl 
phenyl of L-phenylalanine does not affect the orientation of the water to alcohol molecules in the solvent system. Each of the amino acids studied demonstrated an ability to differentiate between the hydroalcoholic solvents used. The quantitative order of solubility in the solvent systems used varied for each amino acid, but similar solubility profiles could be seen for the entire solvent series. Variation of $\mathrm{pH}$ in pure aqueous solvent systems produced an isoelectric band of invariant solubility with a distinct increase in solubility above and below this band. The increase in total solubility of the amino acids is directly proportional to the number of moles of acid or base added. As the nonpolar portion of the amino acid molecule increased, the total resultant solubility per mole of acid or base added also increased.

In an aquears system, the total solubility is equal to the sum of the original zwitterion solubility plus the solubility of the salt that was found. For those amino acids studied, only single salts were formed. In the hydroalcoholic solvent systems, variation of $\mathrm{pH}^{\prime}$ produced minimum solubility at the isoelectric point with no distinct isoelectric band seen. As the percent alcohol increased in those solvent systems studied, similar increments of acid or base added to the system produced a proportionally greater increase in the magnitude of total solubility of the amino acid. This might be attributed to an increase in the importance of the charge species as the polarity of the solvent system decreased as well as the increased affinity of the amino acid for the $\mathrm{Na}^{+}$or $\mathrm{Cl}^{-}$ ion present. 
DOCTOR OF PHILOSOPHY THESIS

OF

THOMAS E. NEEDHAM, JR:

Approved:

Thesis Committee:

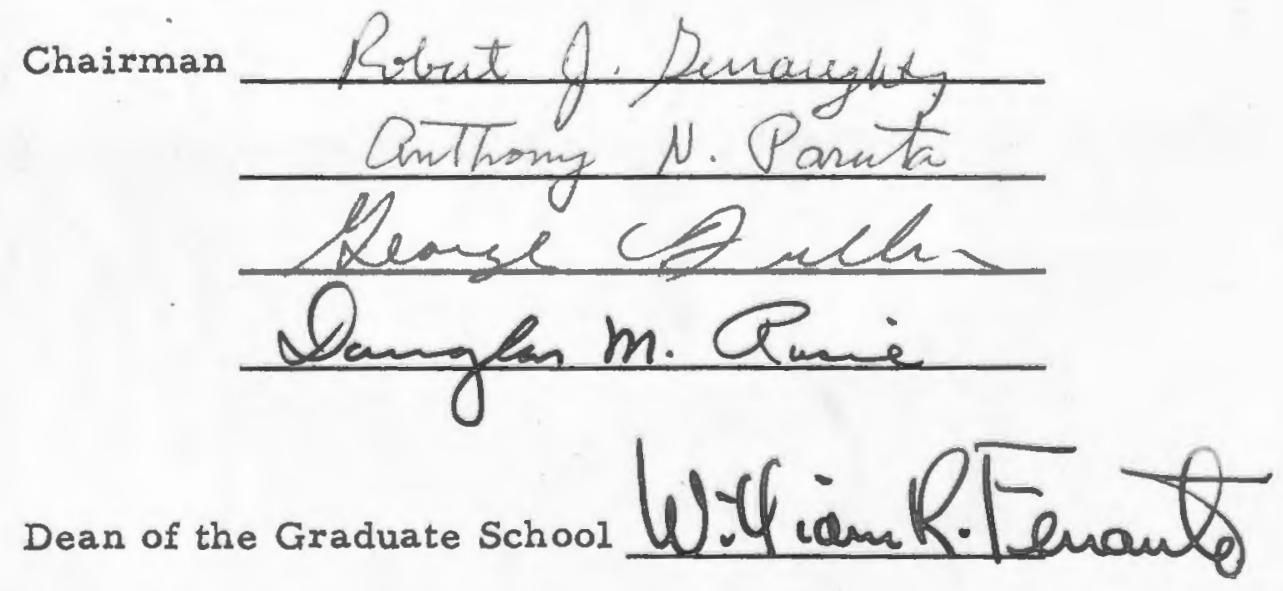

UNIVERSITY OF RHODE ISIAND 


\section{TABLE OF CONTENTS}

PAGE

ABSTRACT • • . . . . . . . • . . . . ii TABLE OF CONTENTS • • • • • • • . . • • iv

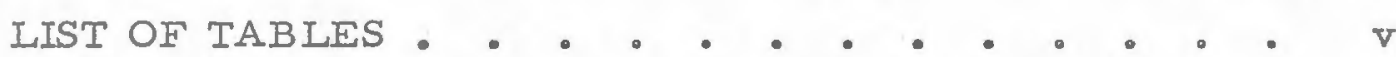

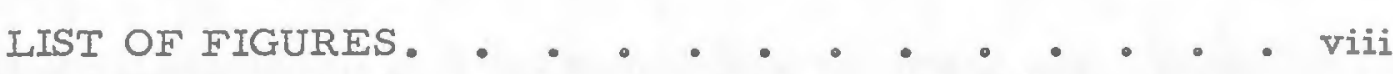

I. INTRODUCTION •. . . . . . . . . . 1

II. EXPERIMENTAL • • • • • • • • • • . 5

III. RESULTS AND DISCUSSION . • • • • • • . 10

IV. CONCLUSIONS : . . . . 75

V. REFERENCES . • • • • • • • • . 78

VI. APPENDIX • • . . . . . . . . 81

I. Program Fitting a Set of Data to a Polynomial Equation. . . . . . . 81

II. Program Computing Least Squares with

a Correlation Coefficient . . . . . . 82 


\section{LIST OF TABIES}

TABLE

PAGE

1. The Molecular Structure of the Amino Acids . . 11

2. The Solubility of the Amino Acids in a Pure Aqueous Solvent System • • • • • • 13

3. The Ratio of the Aqueous Solubilities of the Amino Acids to that of Glycine at $25^{\circ} \mathrm{C}$. . 14

4. The Molar Solubility of the Amino Acids in Methanol-Water Solvent Systems • . . . 18

5. The Molar Solubility of the Amino Acids in Ethanol-Water Solvent Systems . . . .

6. The Molar Solubility of the Amino Acids in n-Propanol-Water Solvent Systems . . . 20

7. The Molar Solubility of the Amino Acids in Isopropanol-Water Solvent Systems . • . .

8. The Molar Solubility of the Amino Acids in Tertiary Butanol-Water Solvent Systems . . 22

9. The Ratio of Solvent Molecules per Solute Molecule in the Methanol-Water Solvent Systems • • • • • • • • • • 30

10. The Ratio of Solvent Molecules per Solute Molecule in the Ethanol-Water Solvent Systems

11. The Ratio of Solvent Molecules per Solute Molecule in the n-Propanol-Water Solvent Systems • • • • • • • • • • • • 
12. The Ratio of Solvent Molecules per Solute Molecule in the Isopropanol-Water Solvent Systems : • . . . . . . . . . .

13. The Ratio of Solvent Molecules per Solute Molecule in the Tertiary Butanol-Water Solvent Systems • • . • • • • • 34

14. The Polynomial Regression Data Generated From the Molar Solubility of Glycine as a Function of Percent Strength of the Solvent System . . . . . . . . . 42

15. The Polynomial Regression Data Generated From the Molar Solubility of L-Alanine as a Function of Percent Strength of the Solvent System . . . . . . . . . . 43

16. The Polynomial Regression Data Generated From the Molar Solubility of L-Valine as a Function of Percent Strength of the Solvent System • • • • • • • • • • . 44

17. The Polynomial Regression Data Generated From the Molar Solubility of L-Phenylalanine as a Function of Percent Strength of the Solvent System . . . • . . • 45

18. The Effect of Adding Acid or Base on the Total Solubility of the Amino Acids in Aqueous Systems . . . . . . 50

19. The Effect of Adding Acid on the Total Aqueous Solubility of the Amino Acids . . .

20. The Effect of Adding Base on the Total Aqueous Solubility of the Amino Acids . . . 54 
21. The First Degree Relationship Between $\mathrm{pH}$ and $\log \left(\mathrm{C}_{\mathrm{A}} / \mathrm{C}_{\mathrm{S}}\right)$ for Acid Addition .

22. The First Degree Relationship Between $\mathrm{pH}$ and $\log \left(\mathrm{C}_{\mathrm{S}} / \mathrm{C}_{\mathrm{A}}\right)$ for Base Addition . .

23. The Effect of Adding Acid or Base on the Solubility of Glycine in Methanol-Water . Solvent Systems • • • • • : • •

24. The Effect of Adding Acid or Base on the Solubility of Glycine in Ethanol-Water Solvent System

25. The Effect of Adding Acid or Base on the Solubility of Glycine in n-Propanol-Water Solvent Systems • • • • • : . .

26. The Effect of Adding Acid or Base on the Solubility of Glycine in Isopropano1-Water Solvent Systems • . • • • • : 62

27. The Effect of Adding Acid or Base on the Solubility of Glycine in Tertiary ButanolWater Solvent Systems 


\section{IIST OF FIGURES}

FIGURE

PAGE

1. The Solubility of the Amino Acids as a

Function of the Number of Carbons

Attached to the $\alpha-A m i n o$ Group . . . .

2. The Molar Solubility of the Amino Acids

in Methanol-Water Solvent Systems . . . 24

3. The Molar Solubility of the Amino Acids

in Ethanol-Water Solvent Systems . . . . 25

4. The Molax Solubility of the Amino Acids

in n-Propanol-Water Solvent Systems . . . 26

5. The Molar Solubility of the Amino Acids

in Isopropanol-Water Solvent Systems . . . . 27

6. The Molar Solubility of the Amino Acids in

Tertiary Butanol-Water Solvent Systems • . 28

7. The Molax Solubility of Glycine in the

Solvent Systems • • • • • • • • 37

8. The Molar Solubility of L-Alanine in the

Solvent Systems • • • • • • . • 38

9. The Molar Solubility of L-Valine in the

Solvent Systems • • • • • . • . 39

10. The Change in Aqueous Solubility of the Amino Acids as a Function of pH . . . . 49

11: The Solubility of the Amino Acids in Pure Methanol as a Function of $\mathrm{pH}^{\prime}$. . . . . 64 
12. The Solubility of the Amino Acids in Pure Ethanol as a Function of $\mathrm{pH}^{\natural}$. . . . . 65

13. The Solubility of the Amino Acids in Pure n-Propanol as a Function of $\mathrm{pH}^{8}$. . . . 66

14. The Solubility of the Amino Acids in Pure

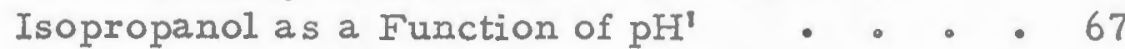

15. The Solubility of the Amino Acids in Pure Tertiary Butanol as a Function of $\mathrm{pH}^{\prime} \cdot$. . 68

16. The Ratio of Total Solubility to Solubility at the Neutral Point for Glycine as a Function of $\mathrm{HCl}$ and $\mathrm{NaOH}$ added in an Ethanol-Water System . . . . . . 69

17. The Ratio of Total Solubility to Solubility at the Neutral Point for L-Alanine as a Function of $\mathrm{HCl}$ and $\mathrm{NaOH}$ added in an Ethanol-Water System . . . . . 70

18. The Ratio of Total Solubility to Solubility at the Neutral Point for L-Valine as a Function of $\mathrm{HCl}$ and $\mathrm{NaOH}$ added in an Ethanol-Water System

19. The Ratio of Total Solubility to Solubility at the Neutral Point for L-Phenylalanine as a Function of $\mathrm{HCl}$ and $\mathrm{NaOH}$ added in an Ethanol-Water System . . . . . . . 


\section{INTRODUCTION}

The importance of amino-acids in viable biological systems is due to the unusual properties of this class of chemical compounds. These substances, possessing both acidic and basic properties within the same molecule, afford the basic linkages leading to complex peptides and proteins, the basic materials of life. Further, ten such amino-acids have been shown to be essential for life processes. Again, due to the basic and acidic character in a given molecule, these substances are dipolar compounds, with either zwitterion species formation or anionic or cationic species formation depending upon the acidity of the fluid environment. The relative concentration of these species, which coexist with each other, depend completely upon the value of $\mathrm{pH}$.

Since there are dissociable groups in these molecules, many studies have been performed to determine the acid and base dissociation constants for the individual amino acids. Cohn and Edsall (I) have tabulated the constants for a large series of the se compounds.

In 1933, Edsall and Blanchard (2) postulated that dissociation 
of the alpha amino acids in aqueous solution was as follows:

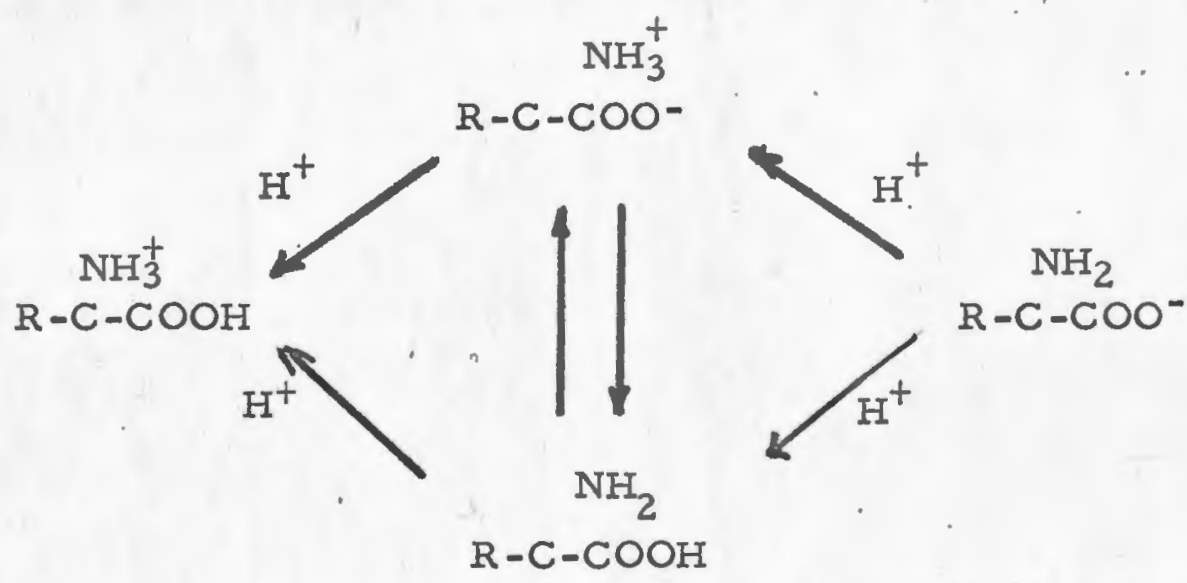

They believed that the charged and uncharged forms were in equilibrium. Further, they expanded a method developed by Ebert (3) to calculate the $\mathrm{K}_{\mathrm{z}}$ of these systems. This ratio of charged to uncharged ions in solution was found to be in the range of $10^{4}$ to $10^{6}$ for most aliphatic amino acids. This theory of the zwitterion or dipolar type configuration has been fürther substantiated by Fox and Foster (4).

An important property of the amino acids is that they exhibit an isoelectric point. This is the point in an electric field at which the zwitterion form will not migrate to either the anode or cathode (5). Also, at the isoelectric point, the sum of the net charge is zero. If we represent the isoelectric point as pI and the dissociation constants as $\mathrm{pK}_{1}$ and $\mathrm{pK}_{2}$, then (6)

$$
\mathrm{pI}=1 / 2 \mathrm{pK}_{1}+1 / 2 \mathrm{pK}_{2}
$$

Literature values of solubility for amino acids are usually expressed as the solubility in pure water or in aqueous systems 
adjusted to a $\mathrm{pH}$ equal to the isoelectric point (7). Since the charged form of the amino acid would be dominant, it was assumed that this type of compound would exhibit a high degree of solubility in water. It was postulated that amino acids would be relatively insoluble in non-aqueous systems due to the inability of the solvents to interact with charged molecules. Blanchard and Edsall (8) studied the solubility of amino acids in several alcohol-water mixtures, and listed the $\mathrm{K}_{\mathrm{z}}$ values of some of the amino acids in concentrated alcoholic solutions. They theorized that solvent systems having lower dielectric constants than water should give a lower ratio of charged to uncharged molecules. 
Statement of the Problem

It was felt judicious to study the solubility of a series of simple alpha amino acids as glycine, L-alanine, L-valine, L-phenylalanine, and DL-amino-octanoic acid in a series of pure and mixed solvent systems and at varying $\mathrm{pH}^{\prime} \mathrm{s}$ above, at, and below the isoelectric point.

It was hoped that some discernable solubility patterns might be evidenced which could be related to the nature and properties of either the amino acids used or the solvent systems studied. Further, it was thought desirable to attempt to relate the solubilities observed to the content of the species at any given $\mathrm{pH}$ in the solvent systems studied. 


\section{EXPERIMENTAL}

Equipment - A standard rotating solubility apparatus ${ }^{1}$ capable of holding multiple samples was immersed in a water bath kept at constant temperature by a heating and circulating pump? The $\mathrm{pH}$ and apparent $\mathrm{pH}^{\prime} \mathrm{s}\left(\mathrm{pH}^{\prime}\right)$ were measured with a Leeds-Northrup pH meter ${ }^{3}$ using a combination electrode. Gravimetric determinations were carried out using a constant temperature drying oven and a Mettler Balance. All water used in pure and mixed solvent systems was deionized using a Barnstead Bantum Demineralizer?

${ }^{1}$ Menold Rotating Apparatus, Lester, Pennsylvania 2 Porta-temp, Precision Scientific Co., Chicago, Illinois. ${ }^{3}$ Leeds-Northrup pH Meter Model \#7401 with AHT single Electrode \#4858-a 15.

${ }^{4}$ Mettler Instrument Corp., Hightstown, New Jersey.

${ }^{5}$ Barnstead Still \& Steriline Co., Boston, Massachusetts. 
Materials - The amino-acids used in this study were as follows: glycine, L-alanine, L-valine, ${ }^{3}$ L-phenylalanine, ${ }^{4}$ DL-amino-octanoic acid.

For the purposes of this study, label purity of the manufacturer was accepted and no pretreatment of the solvents was felt to be necessary.

The water used was deionized using a mixed bed column to a concentration of less than $10 \mathrm{ppm}$ of $\mathrm{NaCl}$ to minimize the possibility of complex formation with any metals usually present (9). The other solvents used were absolute anhydrous methanol, absolute ethanol, n-propanol, iso-propanol ${ }^{9}$ and tertiary-butanol. ${ }^{10}$ All solvents had a listed water content of $0.2 \%$ or less, and a boiling point range of 2 degrees or less.

The hydrochloric acid ${ }^{11}$ and sodium hydroxide ${ }^{12}$ used were solutions of analytical reagent grade.

${ }^{1}$ Lot 070381 - Aldrich Chemical Company, Milwaukee, Wisconsin 2 Lot 113071 - Aldrich Chemical Company, Milwaukee, Wisconsin ${ }^{3}$ Lot 070381 - Aldrich Chemical Company, Milwaukee, Wisconsin ${ }^{4}$ Lot 102471 - Aldrich Chemical Company, Milwaukee, Wisconsin ${ }^{5}$ Eastman Organic Chemicals, Rochester 3, New York ${ }^{6}$ Mallinckrodt chemicals, New Jersey

${ }^{7}$ U. S. Industrial Chemical Company, New York 8 Allied Chemical Company, New Jersey ${ }^{9}$ Allied Chemical Company, New Jersey 10 Mallinckrodt Chemicals, New Jersey 11 Mallinckrodt Chemicals, New Jersey ${ }^{12}$ Mallinckrodt Chemicals, New Jersey 
Methods - Two types of systems were used in this study. The first type of system was the pure and mixed solvents including water, methanol, ethanol, n-propanol, isopropanol and tertiary butanol and mixtures of each with water. The solubility of each of the amino acids used in the study was found in the pure solvent systems and in the mixed solvents systems of $0 \%, 10 \%, 30 \%, 50 \%, 70 \%, 90 \%$ and $100 \%$ $(v / v)$ of methanol-water, ethanol-water, n-propanol-water, isopropanolwater, and tertiary butanol-water. In the second type system, the solubility of each of the series of amino acids was varied by addition of either acid or base.

Procedure - For the first part, the same basic procedure was used for all solvent systems. For each percent strength which was evaluated, three samples of equal volume were prepared from a stock solution. Into each sample bottle, an excess amount of amino acid was added, and the bottle was covered with a cap lined with an inert teflon liner. Since initial studies indicated that the amino acids reached a maximum solubility in one-half to 1 hour, a preliminary rotation period of one hour at room temperature was performed to insure that excess amino acid remained. The samples were then placed into a water bath, which was maintained at a temperature of $25^{\circ} \pm 0.2^{\circ}$, and allowed to reach equilibrium. In 24 hours, either one $\mathrm{ml}$. or five $\mathrm{ml}$. samples were withdrawn from the sample bottles using a pipette with a pledget of 
glass wool on the end as a filtering medium. The size of the sample withdrawn from the bottles was determined by preliminary experimentation in order to minimize the possible error during gravimetric analysis. The withdrawn sample was immediately transferred to a tared vial which was then weighed to determine density. The series of tared vials was then placed in an oven to be evaporated and dried to constant weight. The evaporations were made at a temperature of $95^{\circ} \mathrm{C}$. or less to avoid decomposition of the amino acids. (10) Immediately after sample withdrawal, the $\mathrm{pH}$ or $\mathrm{pH}^{\prime}$ of each solvent system was taken.

In the second part, the interest was twofold and a procedure was designed to maximize the experimental precision in each case. Firstly, in the pure aqueous solvent systems, the interest was in salt formation as well as the variation of total solubility as a function of $\mathrm{pH}$. A procedure was developed to quantitate the amount of acid or bàse present at any given $\mathrm{pH}$. One hundred milliliters of water, a specific amount of an $\mathrm{HCl}$ or $\mathrm{NaOH}$ standardized solution, and an excess of amino acid was mixed in an erlenmeyer flask which was then capped and placed on a magnetic stirrer and allowed to reach equilibrium. In twenty-four hours, a series of at least fifteen 5-milliliter samples were withdrawn from the flask and placed in tared vials. To those samples previously mixed with $\mathrm{HCl}, 5$ accurately measured different amounts of 
$\mathrm{NaOH}$ solution were added in sets of 3 each, so that the pH increased to below that of the isoelectric point. After precipitation, these samples were allowed to equilibrate for 24 hours. The amount of the precipitate as well as the amount of the combined amino acids remaining in the solutions and the $\mathrm{pH}$ of the solutions were determined using the procedure described in section one for gravimetric analysis. A similar process was followed for the samples mixed with standard $\mathrm{NaOH}$ except that $\mathrm{HCl}$ was added in incremented amounts to a $\mathrm{pH}$ above that of the isoelectric point.

In the non-aqueous solvents, the relationship between total amino acid solubility and $\mathrm{pH}^{\prime}$ was the main concern. Initially, four samples of equal volume were prepared for each strength to be evaluated. Excess amino acids were added to each sample, the preliminary rotation performed, and the samples placed into the water bath at $25^{\circ} \mathrm{C}$. and allowed to equilibrate. In 24 hours, one $\mathrm{ml}$. samples were withdrawn, the $\mathrm{pH}$ or $\mathrm{pH}^{\prime}$ taken, and the samples were analyzed gravimetrically. Into two of the samples, incremental amounts of acid were added in succeeding 24 hour periods and the $\mathrm{pH}$ or $\mathrm{pH}^{3}$ as well as a gravimetric analysis performed on the aliquots taken during each period. Into the remaining samples, base was added and a similar analysis prepared. The sample size and number of samples was adjudged sufficient since good agreement was found among succeeding samples for the increase in total solubility of the amino acids. 


\section{RESULTS AND DISCUSSION}

The solubilities of the amino acids studied were determined in water, methanol, ethanol, n-propanol, isopropanol, and tertiary butanol at $25^{\circ} \mathrm{C}$.

To illustrate the physical and chemical relationships of the amino acids studied, their structural formulas are shown in Table 1. It can be seen that all the amino acids studied were alpha amino acids. The $\mathrm{D}$ or $\mathrm{L}$ prefixed to the name of the amino acid indicates the configurational relationship of the structural groups about the asymetric carbon atom. A DL prefix indicates a racemic compound or optically inactive mixture of the stereoisomers. A $(+)$ or $(-)$ after the initial letter prefix may be used to show the direction of rotation of polarized light, but is not usually necessary since no differences in physical or chemical properties are induced by this property. (11)

It can be seen that variation in solubility characteristics of the se amino acids can be attributed to differences in their chemical structure. Starting with glycine as the basic unit, L-alanine is $\alpha$-methyl glycine and the difference in solubility would then be a result of the special configuration and polarity effect of the additional methyl group. Further,

in this series, the effect of the following $\alpha$ groups are being studied: the isopropyl group, the methyl phenyl group, and the six carbon n-alkyl group. 
TABLE 1.

MOLECUIAR STRUCTURE OF THE AMINO ACIDS

Glycine

L-Alanine

L-Valine

L-Phenylalanine

DL-Amino-octanoic Acid
$\mathrm{H}_{2} \mathrm{~N}-\mathrm{CH}_{2} \mathrm{COOH}$

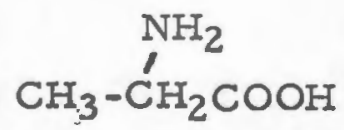

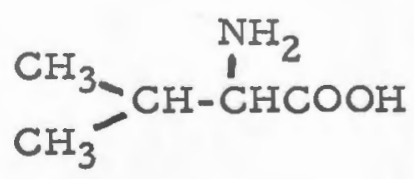

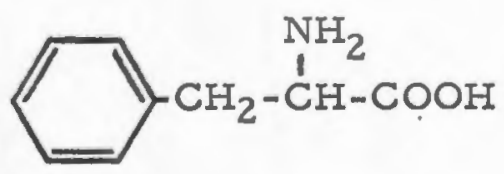

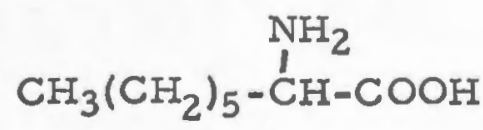


By use of Raman Spectroscopy (12, 13), melting point data (14), changes in molecular volume (15), and dielectric constant measurements (16), the amino acid has been shown to exist as dipolar ions in solution. The zwitterionic character of the amino acid gives it a high aqueous solubility due to its attraction to the dipolar water molecules. Table 2 shows the solubility of the amino acids studied in water at $25^{\circ} \mathrm{C}$. These values correspond to a good degree with the range of literature values previously reported. $(17,18)$

Since glycine is being considered the basic common structural unit in each of the amino acids, its use as the standard in comparing solubility differences of the other amino acids would logically follow. Table 3 illustrates the ratio of solubility of an amino acid in $\mathrm{gm} . / \mathrm{ml}$. as compared to the solubility of glycine in water. It can be seen that the addition of a methyl group to the basic glycine molecule reduces solubility by 34 percent, while the addition of the isopropyl group reduces solubility by 73 percent.

The effect on solubility by the addition of $\mathrm{CH}_{2}$ groups and by aromatic substitution is further illustrated in Figure 1, where the solubility of each amino acid in $\mathrm{gm} . / \mathrm{ml}$. is plotted against the number of carbons in that structure attached to the basic glycine unit. A smooth non-linear correlation is observed for the measure of decreasing polarity in the alkyl substituted amino acids. In the case of L-phenylalanine, it can be as sumed that the solubility of an aromatic 
TABLE 2.

SOLUBILITY OF AMINO ACIDS

IN A

PURE AQUEOUS SOLVENT SYSTEM AT $25^{\circ} \mathrm{C}$.

\begin{tabular}{lc}
\hline Amino Acid & Solubility ${ }^{\mathrm{a}}(\mathrm{gm} . / \mathrm{ml}$ ) \\
\hline Glycine & .2178 \\
L-Alanine & .1450 \\
L-Valine & .0559 \\
L-Phenylalanine & .0294 \\
DL-Amino-octanoic acid & .0005 \\
\hline
\end{tabular}

${ }^{\mathrm{a}}$ Each solubility is the average of at least 4 determinations. 
TABLE 3.

THE RATIO OF THE AQUEOUS SOLUBILITIES

OF AN AMINO ACID TO THAT OF GLYCINE AT $25^{\circ} \mathrm{C}$.

\begin{tabular}{ll}
\hline Amino Acid & $\operatorname{Ratio}^{a}\left(\frac{S x}{S_{\text {glycine }}}\right)$ \\
\hline Glycine & 1.0 \\
L-Alanine & 0.66 \\
L-Valine & 0.27 \\
L-Phenylalanine & 0.14 \\
DL-Amino-octanoic Acid & 0.002 \\
\hline
\end{tabular}

${ }^{a}$ Each solubility used in calculating the ratio is in $\mathrm{gm} . / \mathrm{ml}$. and is the average of at least eight determinations. 


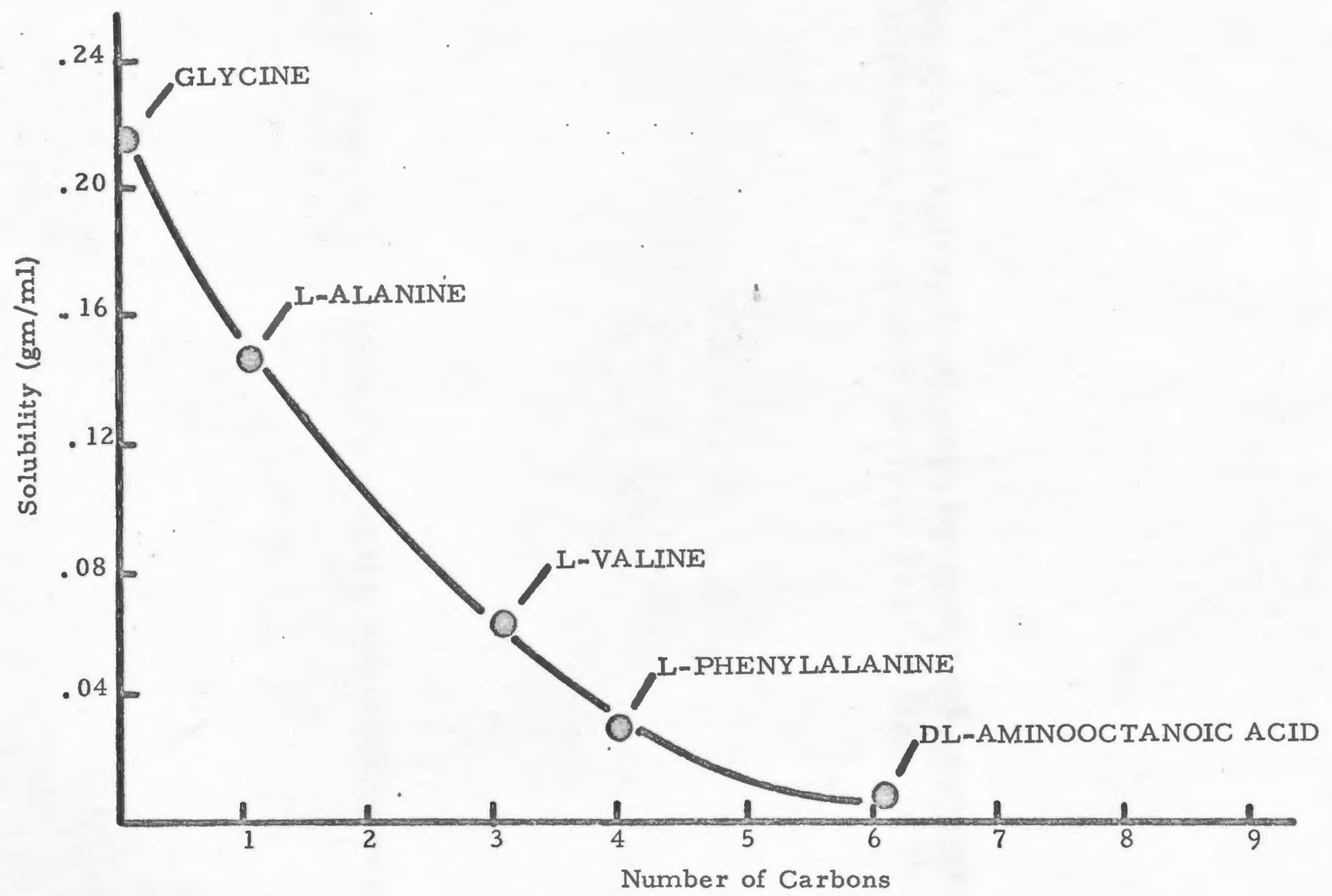

Figure 1. The Solubility of the Amino Acids as a Function of the Number of Carbons Attached to the $\propto$ Amino Group. 
ring is approximately equivalent to three $\mathrm{CH}_{2}$ groups (19). Then the correlation of this aromatic amino acid into the smooth non-linear line of decreasing polarity further substantiates the use of glycine as a basic: solubility unit. Now that it has been shown that an increase in the number of carbon atoms decreases solubility $(20,21)$ and that glycine is the basic soiubility unit, then it would seem that the total amino acid solubility is dependent on both the polar and nonpolar portions of the molecule.

The addition of a semi-polar liquid to the polar aqueous solvent to form a binary solvent system would be expected to cause a change in the solubility behavior of the amino acids by providing an environment of continuously decreasing polarity. As the concentration of semi-polar liquid is increased, the binary solvent medium would continually decrease the polarity to the point of the pure semi-polar liquid. In this way, the polarity of the system is changed in discrete steps by increasing the alçoholic content.

In a solvent system of decreasing polarity, the differences in solubility of these amino acids studied would be dependent on the basic -amino carboxylic acid and the remaining aliphatic or aromatic portion of the structure. In solution the $\alpha$-amino carboxylic acid portion of the molecule is present as a charged species in equilibrium with an uncharged species. (22)

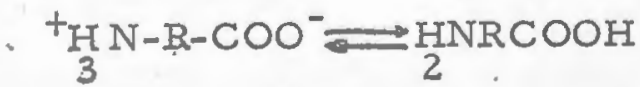


The $\mathrm{K}_{\mathrm{z}}$ which is the $:$; of the charged to uncharged species, has been shown to decrease as the polarity of the solvent system is reduced. Edsall and Blanchard (23) demonstrated a reduction in $\mathrm{K}_{\mathrm{z}}$ of 263,000 to 1000 for glycine as the polarity of a solvent system was changed from pure water to 90 percent ethanol.

It has been shown (24) that the amino acids exist predominately as charged dipoles even in semi-polar solvents. If the attraction which causes the solubility of the amino acid dipoles is defined as being due to the highly polar water molecules, and the semi-polar solvents are assumed to have too little polarity to cause any appreciable solubility of the charged portion of the amino acids, then it would be expected that any reduction in solubility of the amino acids would be directly proportional to a decrease in the aqueous content or polarity of the solvent system.

This assumption of amino acid solubility behavior can be shown in several ways. In Tables 4-8, the molar solubility of the amino acids studied is shown in $0 \%, 10 \%, 30 \%, 50 \%, 70 \%, 90 \%$, and $100 \%$ $(v / v)$ solutions of methanol, ethanol, $n$-propanol, isopropanol, and tertiary butanol. A reduction in solubility is seen in each solvent for glycine, L-alanine, L-valine, and L-phenylalanine as the percent of alcohol was increased. Therefore, it would seem in the case of the se four amino acids that the charged portion of the molecule dominates the solubility characteristics of the entire molecule. The DL-amino- 
TABLE 4.

MOLAR SOLUBILITY OF AMINO ACIDS

IN

METHANOL-WATER SOLVENT SYSTEMS

\begin{tabular}{lllll}
\hline $\begin{array}{l}\text { Percent } \\
\text { Methanol } \\
(\mathrm{v} / \mathrm{v})\end{array}$ & Glycine & L-Alanine & L-Valine & L-Phenylalanine \\
\hline 0 & 2.90 & 1.63 & .474 & .172 \\
10 & 1.74 & 1.39 & .366 & .143 \\
30 & .658 & .743 & .207 & .099 \\
50 & .212 & .364 & .122 & .084 \\
70 & .099 & .120 & .091 & .070 \\
90 & .017 & .026 & .025 & .022 \\
100 & .009 & .012 & .013 & \\
\hline
\end{tabular}

${ }^{a}$ Each value is an average of at least three determinations. 
TABLE 5.

MOLAR SOLUBILITY OF AMINO ACIDS

IN

ETHANOL-WATER SOLVENT SYSTEMS

\begin{tabular}{lllll}
\hline $\begin{array}{l}\text { Percent } \\
\text { Ethanol } \\
(\mathrm{v} / \mathrm{v})\end{array}$ & Glycine & L-Alanine & L-Valine & I-Phenylalanine \\
\hline 0 & 2.90 & 1.63 & .474 & .172 \\
10 & 2.03 & 1.28 & .362 & .143 \\
30 & .811 & .695 & .181 & .092 \\
50 & .296 & .311 & .093 & .078 \\
70 & .077 & .076 & .044 & .050 \\
90 & .013 & .016 & .011 & .014 \\
100 & .004 & .002 & .003 & .002 \\
\hline
\end{tabular}

${ }^{a}$ Each value is an average of at least three determinations. 
TABLE 6.

MOLAR SOLUBILITY OF AMINO ACIDS

IN

n-PROPANOL-WATER SOLVENT SYSTEMS

\begin{tabular}{lllll}
\hline $\begin{array}{l}\text { Percent } \\
\text { n-Propanol } \\
(\mathrm{v} / \mathrm{v})\end{array}$ & Glycine & L-Alanine & L-Valine & L-Phenylalanine \\
\hline 0 & 2.90 & 1.63 & .474 & .172 \\
10 & 1.99 & 1.22 & .395 & .142 \\
30 & 1.03 & .682 & .255 & .134 \\
50 & .486 & .356 & .175 & .127 \\
70 & .122 & .110 & .056 & .078 \\
90 & .008 & .009 & .009 & .013 \\
100 & .011 & .002 & .003 & .002 \\
\hline
\end{tabular}

a Each value is an average of at least three determinations. 
TABLE 7.

MOLAR SOLUBILITY OF AMINO ACIDS

IN

ISO-PROPANOL-WATER SOLVENT SYSTEMS

\begin{tabular}{lllll}
$\begin{array}{l}\text { Percent } \\
\text { Isopropanol } \\
(\mathrm{V} / \mathrm{V})\end{array}$ & Glycine & L-Alanine & L-Valine & L-Phenylalanine \\
\hline 0 & 2.9 & 1.63 & .474 & .172 \\
10 & .06 & 1.23 & .343 & .123 \\
30 & .857 & .627 & .178 & .093 \\
50 & .365 & .274 & .097 & .076 \\
70 & .081 & .070 & .039 & .047 \\
90 & .008 & .006 & .006 & .009 \\
100 & .004 & .005 & .003 & .001 \\
\hline
\end{tabular}

${ }^{a}$ Each value is an average of at least three determinations 
TABLE 8.

MOLAR SOLUBILITY OF AMINO ACIDS

IN

TERTIAR Y-BUTANOL-WATER SOLVENT SYSTEMS

\begin{tabular}{lllll}
\hline $\begin{array}{l}\text { Percent } \\
\begin{array}{l}\text { Tertiary } \\
\text { butanol } \\
(\mathrm{v} / \mathrm{v})\end{array}\end{array}$ & Glycine & L-alanine & L-Valine & L-Phenylalanine \\
\hline 0 & 2.9 & 1.63 & .474 & .172 \\
10 & 1.93 & 1.19 & .349 & .127 \\
30 & .941 & .632 & .180 & .094 \\
50 & .456 & .308 & .094 & .076 \\
70 & .109 & .085 & .043 & .005 \\
90 & .005 & .005 & .009 & .001 \\
100 & .004 & .001 & .007 & \\
\hline
\end{tabular}

${ }^{a}$ Each value is an average of at least three determinations 
octanoic acid with a low solubility in those solvent systems used, was not included in the above tables, since it was felt that accurate differentiation in solubilities could not be determined. However, for this amino acid it would seem that the nonpolar-polar ratio has reached the point where the high charge of the dipolar portion of the molecule is balanced by the non-polar six carbon n-alkyl chain to produce an invariant solubility. This would seem to correlate with the findings of Cohn (25) in which most $\alpha$-amino acids were found to be less soluble in ethanol or ethanol-water mixtures than in water, and as the side chains lengthened a point was reached where the ethanolic solubility was greater than the aqueous solubility.

Figures 2-6 illustrate the variation in molar solubility of the amino acids as the percent strength of the semi-polar solvents is increased. The decrease in solubility can be seen to be a non-linear curve rather than the proportional linear decrease which would be expected as the polarity of the solvent system was decreased in discrete increments. In methanol-water and ethanol-water solvent systems, glycine shows a greater decrease in solubility than L-alanine as the percent alcohol is increased. This correlates with the work of Dunn and Ross (26) which shows the same crossover in solubilities as the percent ethanol was increased. In the remaining solvents the solubility decreases in an orderly non-linear fashion with a merging of values at high alcoholic concentrations. It would seem that as the overall polarity 


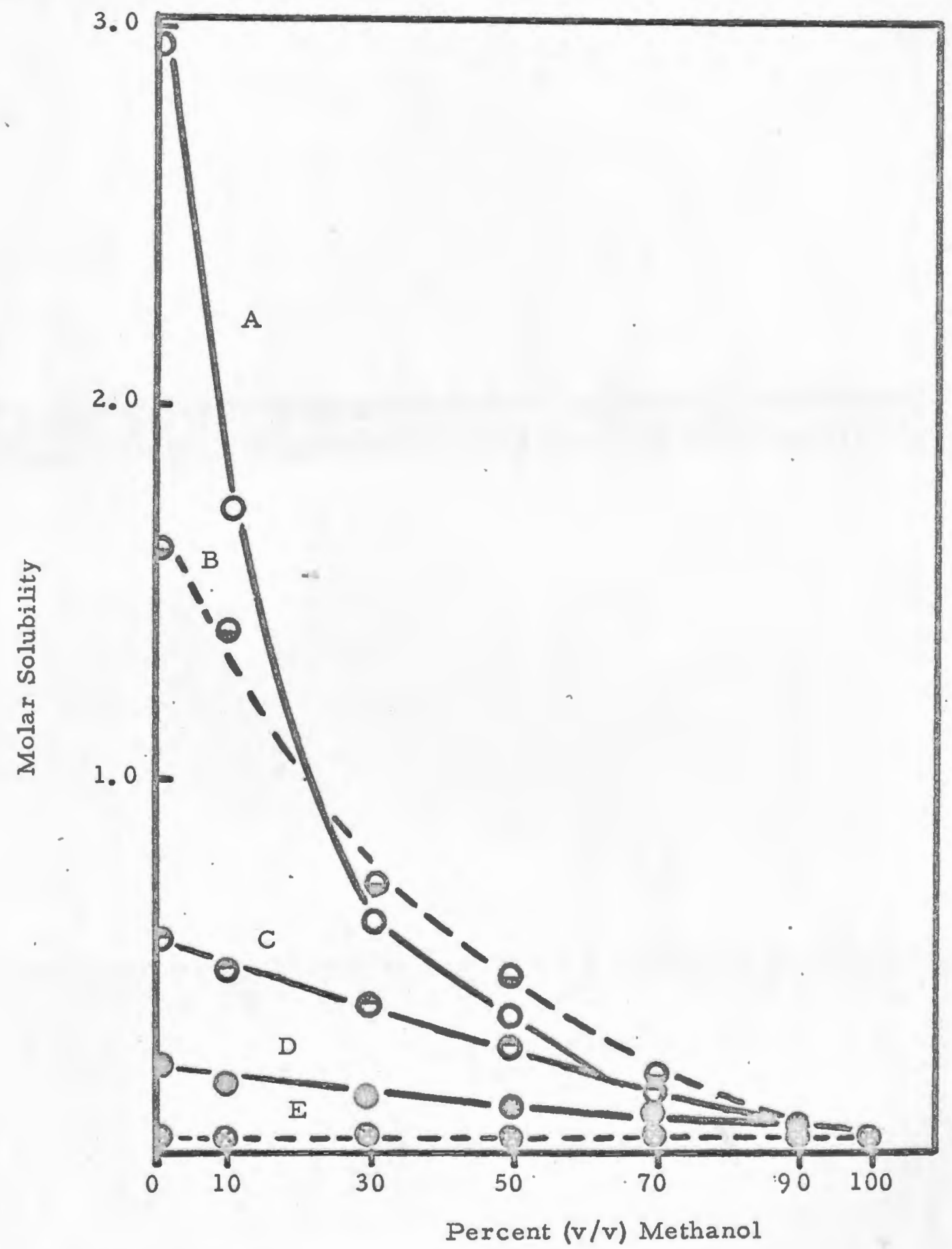

Figure 2. The Molar Solubility of Amino Acid in Methanol-Water Solvent Systems. Curve A - Glycine, Curve B - L-Alanine, Curve C - I-Valine, Curve D-I-Phenylalanine, Curve EDL-Aminooctanoic Acid. 


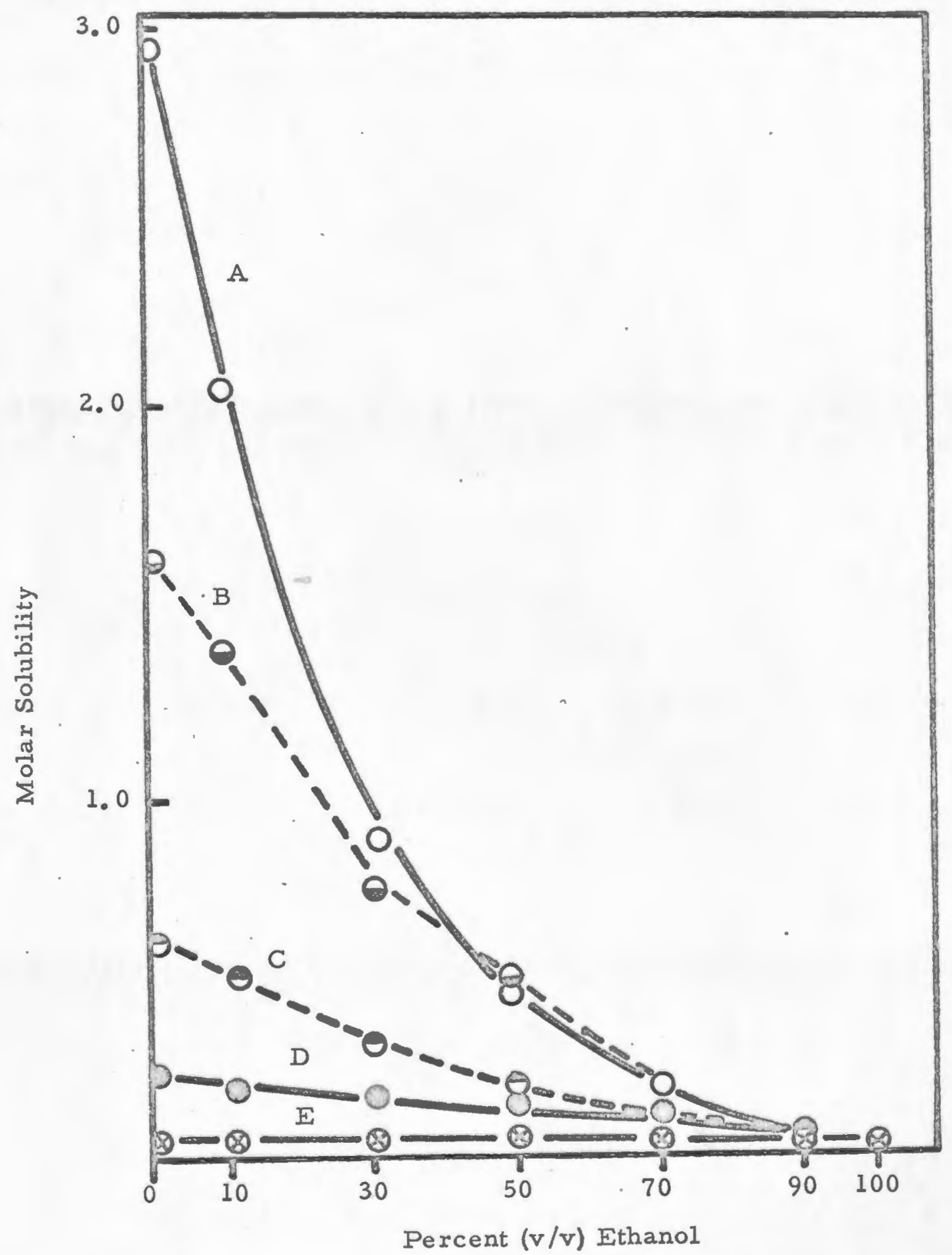

Figure 3. The Molar Solubility of Amino Acid in Ethanol-Water Solvent Systems. Curve A - Glycine, Curve B - L-Alanine, Curve C - L-Valine, Curve D - L-Phenylalanine, Curve E DL-Aminooctanoic Acid. 


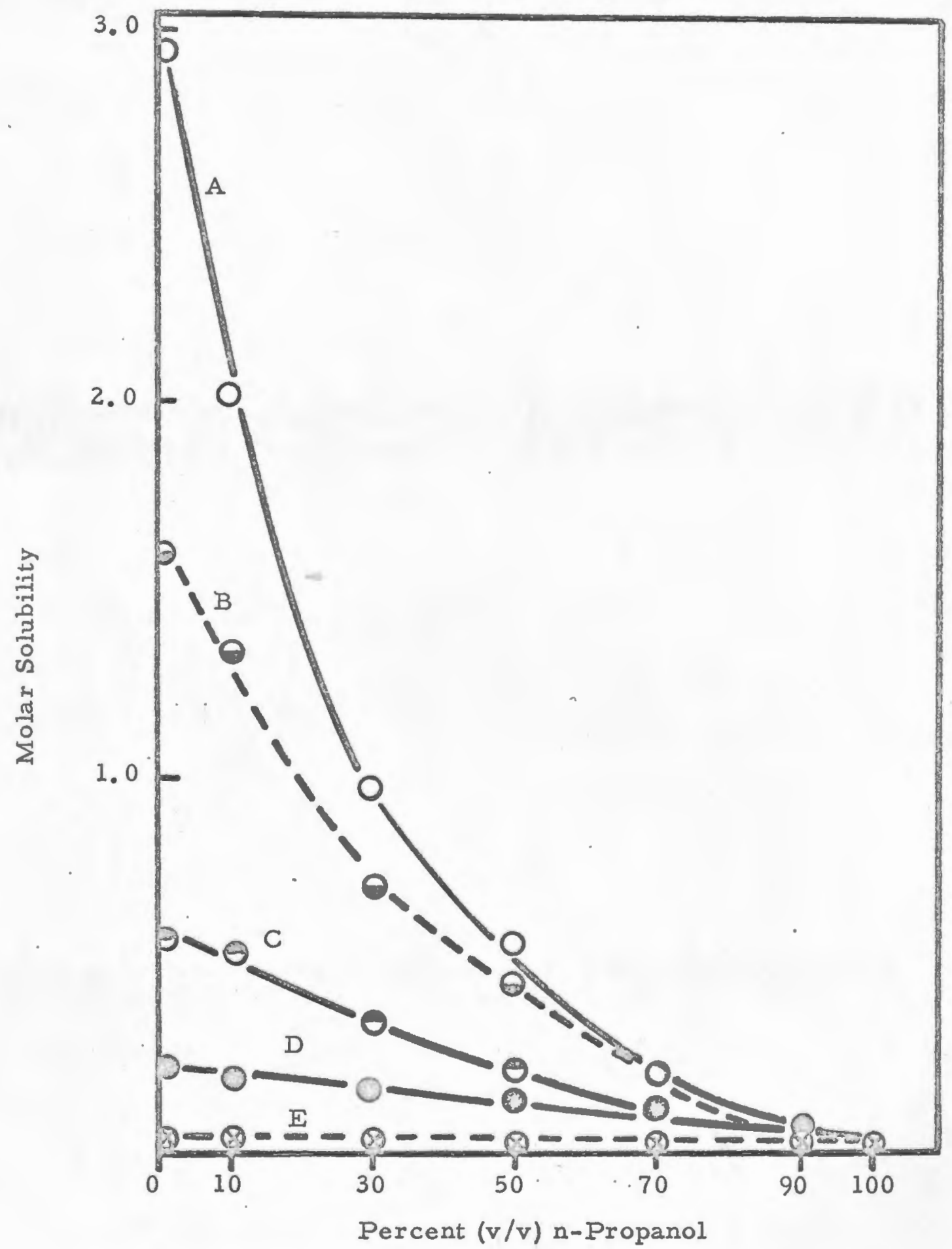

Figure 4. The Molar Solubility of Amino Acid in n-PropanolWater Solvent Systems. Curve A - Glycine, Curve B L-Alanine, Curve C - L-Valine, Curve D - L-Phenylalanine, Curve E - DL-Aminoocatanoic Acid. 


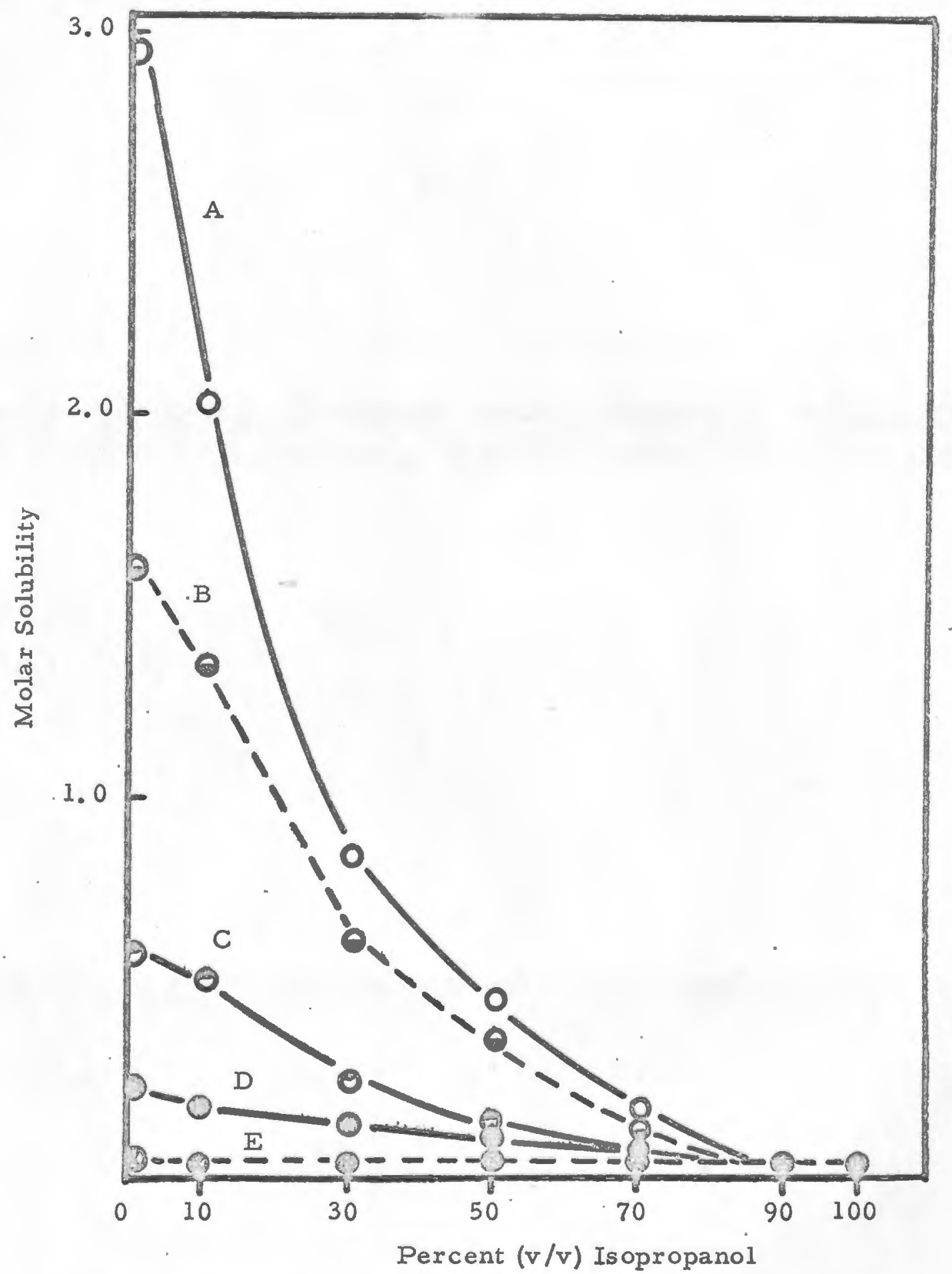

Figure 5. The Molar Solubility of Amino Acid in IsopropanlWater Solvent Systems. Curve A - Glycine, Curve B L-Alanine, Curve C - L-Valine, Curve D - L-Phenylalanine, Curve E - DL-Aminooctanoic Acid. 


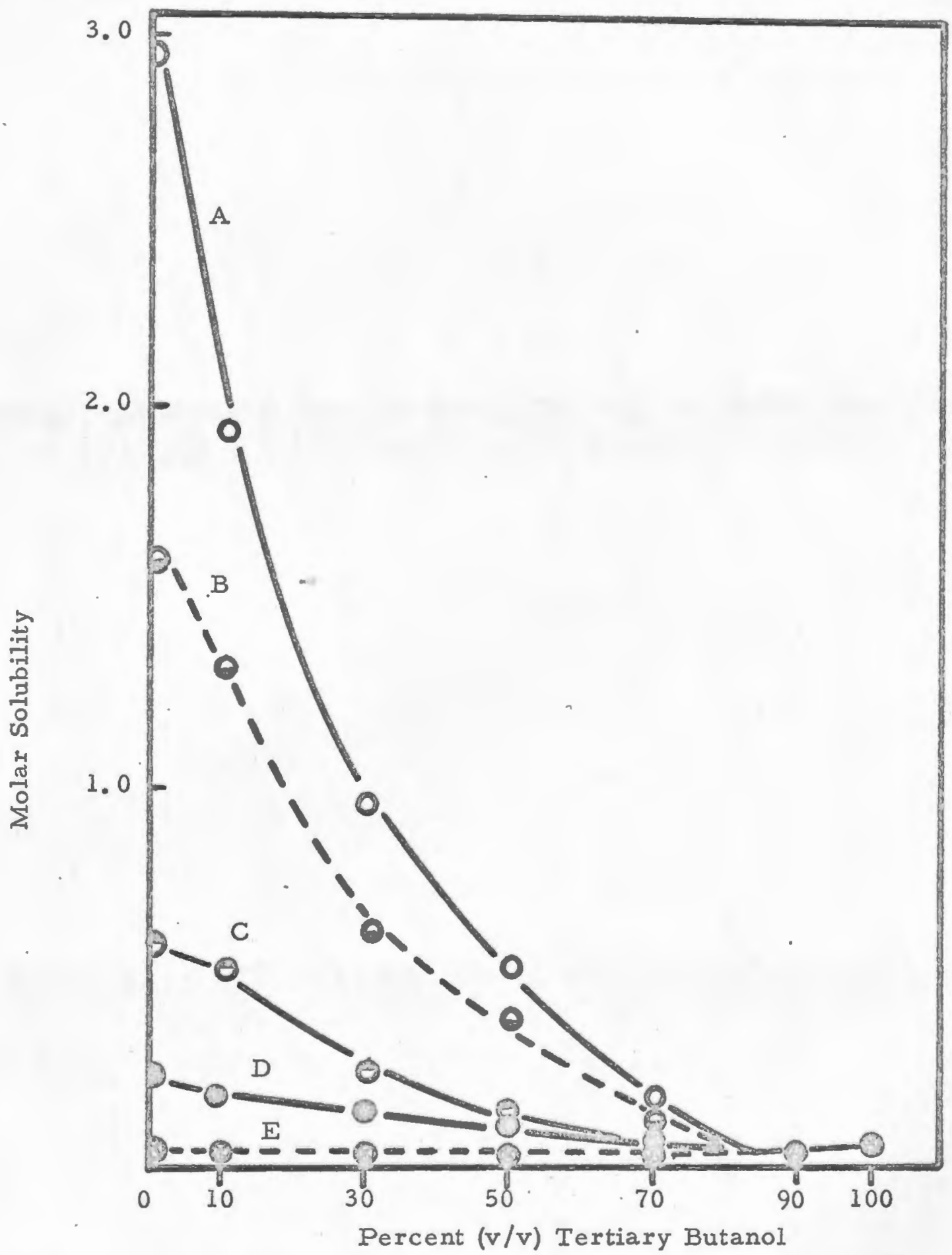

Figure 6. The Molar Solubility of Amino Acids in Tertiary ButanolWater Solvent Systems. Curve A - Glycine, Curve B L-Alanine, Curve C - L-Valine, Curve D - L-Phenylalanine, Curve E - DL-Aminooctanoic Acid. 
of the different solvent systems is decreased, the amino acid solubility decreases in a more regular manner.

By calculating the molarity of each component and determining the density, the mole fraction and the average number of solvent molecules per solute molecule can be calculated. For example, in pure water, the solubility of glycine is 2.9 molar and water is 46.8 molar and, using the density to calculate the mole fraction, glycine is found to be equal to 0.058 and water equals 0.942 . Dividing through by the mole fraction of glycine, it is found that for each molecule of glycine, there is an average of 16 water molecules present. In this way, the effect of an increase in the nompolar-polar ration on the solubility characteristics of each of the amino acids can be shown more clearly. In Tables 9-13, the ratio of solvent per solute molecules in $0 \%, 10 \%, 30 \%, 50 \%, 70 \%, 90 \%$, and $100 \%(\mathrm{v} / \mathrm{v})$ is seen for each of the solvents studied. In a pure aqueous system at saturation solubility, each molecule of glycine has 16 molecules of water available for interaction. L-alanine has 30, L-valine has 110, and I-phenylalanine has 308. In columns one and two for each amino acid, the watersolute and semipolar solvent-solute relationship can be seen. This relationship between the solute and the components of the mixed solvent system can be calculated by using the experimentally determined density of the system and the molar solubility of the amino acid. Firstly, the mole fraction of the amino acid as related to the entire solvent system is calculated. Then the mole fraction of each of the remaining solvent 
TABLE 9.

THE RATIO OF SOJ_VET MOLECULES PIR SOLUTE MOLECULE

IN THE METHANOL..WATER SOLVENT SYSTEMS AT $25^{\circ} \mathrm{C}$

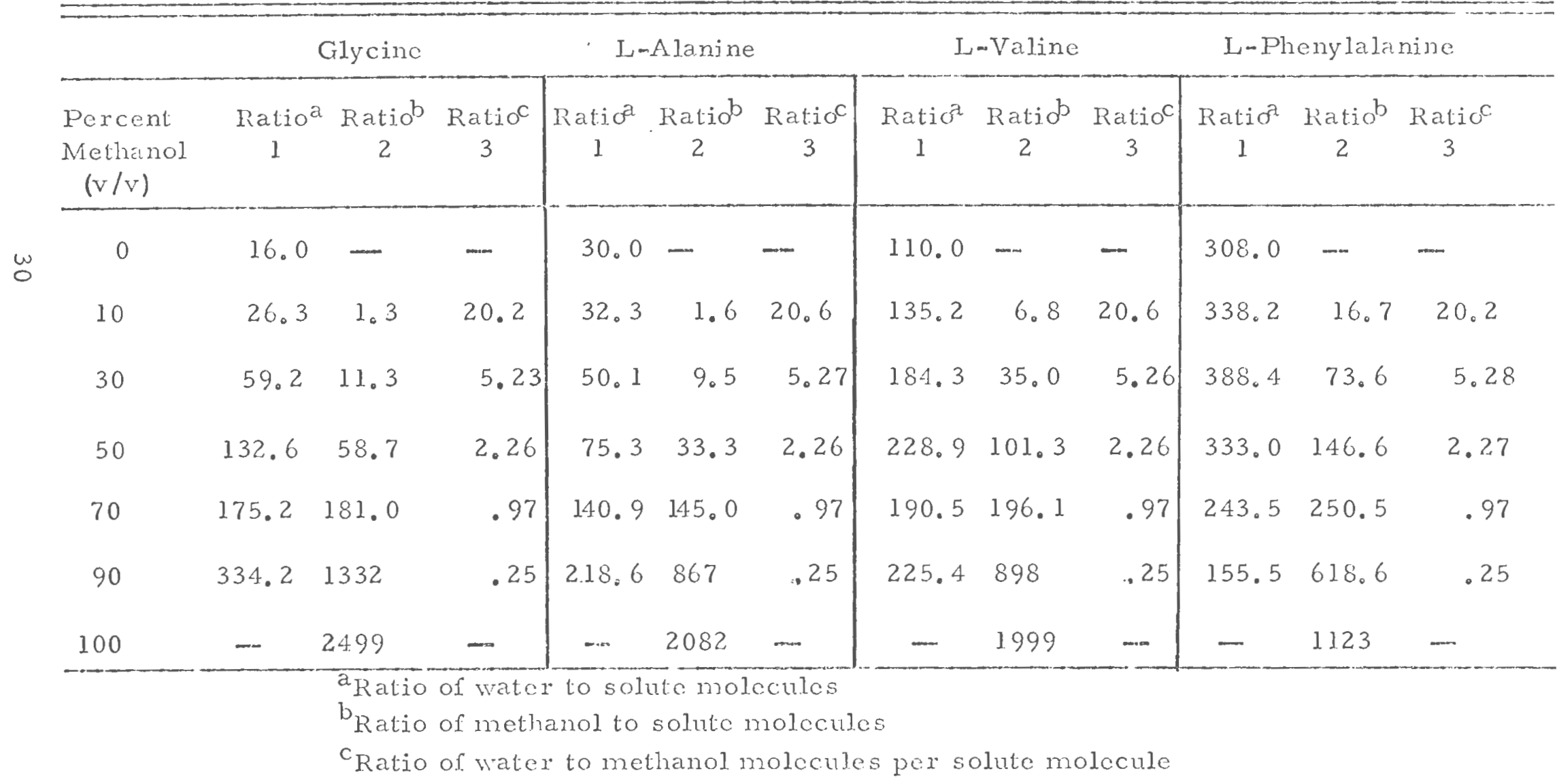


TABLE 10.

THE RATIO OF SOLVENT MOLECULES PER SOLUTE MOLECULE

IN THE ETHANOL WATER SOLVENT SYSTEMS AT $25^{\circ} \mathrm{C}$

\begin{tabular}{|c|c|c|c|c|c|c|c|c|c|c|c|c|}
\hline & \multicolumn{3}{|c|}{ Glycine } & \multicolumn{3}{|c|}{ L-Alanine } & \multicolumn{3}{|c|}{ L-Valine } & \multicolumn{3}{|c|}{ L-Phenylalanine } \\
\hline $\begin{array}{c}\text { Porcent } \\
\text { Ethanol } \\
(\mathrm{v} / \mathrm{v})\end{array}$ & $\begin{array}{c}\text { Ratio } \\
1\end{array}$ & $\operatorname{Ratio}_{2}$ & $\underset{3}{\operatorname{Ratioc}}$ & $\operatorname{Ratio}_{1}^{a}$ & ${ }_{2}^{\text {Ratio }}$ & $\begin{array}{c}\text { Ratiod } \\
3\end{array}$ & $\operatorname{latio}_{1}$ & ${ }_{2}^{\text {Ratiob }}$ & $\underset{3}{\text { Ratiod }}$ & $\begin{array}{c}\text { Ratio } \\
1\end{array}$ & $\frac{2}{2}$ & $\begin{array}{c}\text { Ratiuc } \\
3\end{array}$ \\
\hline 0 & 16.0 & - & - & 30.0 & $-\cdots$ & - & 110.0 & - & - & 308.0 & - & - \\
\hline 10 & 22.6 & .76 & 29.9 & 35.7 & 1.212 & 29.4 & 132.6 & 4.42 & 30,0 & 339.6 & 11.6 & 29.3 \\
\hline 30 & 45.7 & 5.95 & 7.68 & 53.2 & 6.96 & 7.63 & 213.3 & 27.9 & 7.66 & 420.3 & 54.8 & 7.68 \\
\hline 50 & 95.1 & 29.0 & 3.28 & 87.4 & 26.6 & 3.29 & 297.4 & 90.7 & 3.28 & 352.4 & 107.4 & 3.28 \\
\hline 70 & 224.2 & $15 \% 6$ & 1.40 & 220.0 & 156.2 & 1.41 & 381.1 & 271.2 & 1.41 & 333.4 & 237.1 & 1.41 \\
\hline 90 & 445.0 & 1220 & .37 & 356.0 & 976 & .37 & 523.5 & 1435 & .37 & 404.6 & 1109 & . 37 \\
\hline 100 & - & 4999 & - & - & 9090 & - & - & 5881 & - & - & 9090 & - \\
\hline
\end{tabular}


TABLE 11.

THE RATIO OI SOLVENT MOLECUI,ES PER SOLUTE MOLECULE

IN THE n-PROPANOL WATER SOLVENT SYSTEMS AT $25^{\circ} \mathrm{C}$

\begin{tabular}{|c|c|c|c|c|c|c|c|c|c|c|c|c|}
\hline \multirow[b]{2}{*}{$\begin{array}{l}\text { Percent } \\
\text { n-Propanol } \\
(\mathrm{v} / \mathrm{v})\end{array}$} & \multicolumn{3}{|c|}{ Glycinc } & \multicolumn{3}{|c|}{. L-Alanine } & \multicolumn{3}{|c|}{ L-Valine } & \multicolumn{3}{|c|}{ L-Phenylalanine } \\
\hline & $\begin{array}{c}\text { Ratio } \\
1\end{array}$ & $\underset{2}{a}$ Ratio & $\underset{3}{\operatorname{Ratio}}$ & ${ }_{1}^{\text {Ratio }}$ & ${ }_{2}^{\text {Ralio }}$ & $\begin{array}{c}\text { Ratio } \\
3\end{array}$ & ${ }_{1}^{\text {Ralio }}$ & ${ }_{2}^{\text {Ratio }}$ & $\begin{array}{c}\text { Ratio } \\
3\end{array}$ & $\operatorname{Ratio}_{1}^{\circ}$ & ${ }_{2}^{a} \operatorname{Ratio}^{b}$ & $R_{3}$ \\
\hline 0 & 16.0 & - & - & 30.0 & - & - & 110.0 & - & - & 307.6 & - & $-\cdots$ \\
\hline 10 & 22.2 & 0.5 & 37.3 & 38.0 & 1.0 & 38.0 & 119.3 & 3.1 & 38.7 & 344.6 & 8.9 & 38.9 \\
\hline 30 & 35.4 & 3.6 & 9.84 & 54.4 & 5.5 & 9.81 & 146.3 & $11_{0} 8$ & 9.90 & 281.1 & 28.6 & 9.84 \\
\hline 50 & 53.1 & 12.6 & 4.21 & 74.8 & 17.7 & 4.23 & 154.2 & 36.7 & 4.21 & 208.2 & 49.4 & 4.22 \\
\hline 70 & 133.0 & 73.4 & 1.81 & 151.3 & 83.5 & 1.81 & 289.6 & 159.9 & 1.81 & 209.21 & 116.0 & 1.80 \\
\hline 90 & 694.0 & 1478 & 0.47 & 652.2 & 1308 & 0.50 & 631.2 & 1329 & 0.48 & 431.2 & 919 & 0.47 \\
\hline 100 & - & 1110 & - & $\ldots$ & 6666 & - & - & 4544 & - & - & 6666 & -- \\
\hline
\end{tabular}


TABLE 12 。

THE RAIIO OF SOLVFNT MOLECULES PHR SOLUTE MOIAECULE

IN THE ISOLROPANOL..WATER SOI,VENT SYSTEMS AT $25^{\circ} \mathrm{C}$ 。

\begin{tabular}{|c|c|c|c|c|c|c|c|c|c|c|c|c|}
\hline \multirow[b]{2}{*}{$\begin{array}{l}\text { Percent } \\
\text { Isopropanol } \\
(\mathrm{v} / \mathrm{v})\end{array}$} & \multicolumn{3}{|c|}{ Glycine } & \multicolumn{3}{|c|}{$L-\wedge$ lanine } & \multicolumn{3}{|c|}{$L-V a] j$ jne } & \multicolumn{3}{|c|}{ L-Phenylatanine } \\
\hline & $\operatorname{Ratio}_{1}^{a}$ & $\operatorname{Ralio}_{2}^{b}$ & $\operatorname{Ratio}_{3}{ }^{\mathrm{C}}$ & $\begin{array}{c}\text { Ratio a } \\
1\end{array}$ & $\operatorname{Ratio}_{2}^{b}$ & $\frac{\text { Retio }}{3}$ & $\begin{array}{c}\text { Rallio á } \\
1\end{array}$ & $\operatorname{Ralio}_{2}$ & $\frac{\text { Ratioc }}{3}$ & $\begin{array}{c}\text { Ratio } \\
1\end{array}$ & $\underset{2}{\operatorname{Ratio}}$ & $\operatorname{Ratio}_{3}^{C}$ \\
\hline 0 & 16.0 & $\ldots-$ & - & 30.0 & $-\infty$ & - & 110.0 & - & - & 308.0 & - & - \\
\hline 10 & 21.7 & 0.56 & 38.8 & 36.8 & 0.98 & 38.0 & 133.3 & 3.44 & 38.7 & 400.1 & 10.3 & 38.9 \\
\hline 30 & 42.4 & 4.2 & 10.0 & 58.9 & 5.9 & 9.9 & 213.9 & 21.5 & 10.0 & 417.9 & 41.9 & 10.0 \\
\hline 50 & 73.9 & 17.0 & 4.35 & 97.1 & 22.7 & 4.37 & 281.6 & 65.9 & 4.30 & 359.4 & 84.0 & 4.30 \\
\hline 70 & 215.0 & 117.3 & 1.83 & 232.9 & 127.1 & 1.83 & 418.6 & 229.9 & 1.82 & 349.0 & 190.3 & 1.84 \\
\hline 90 & 735.0 & 1765 & 0.42 & 919.6 & 1937 & 0.47 & 946.2 & 1994 & 0.48 & 619.0 & 1304 & 0.48 \\
\hline 100 & - & 3332 & - & $\cdots$ & 2563 & $-m$ & $\ldots$ & 4347 & - & - & 14284 & $\cdots$ \\
\hline
\end{tabular}


TABLE 13.

THE RATIO OF SOLVENT MOLECULES PER SOLUTE MOLECULE

IN THE TERTIARY BUTANOL-WATER SOLVENT SYSTEMS AT $25^{\circ} \mathrm{C}$.

\begin{tabular}{|c|c|c|c|c|c|c|c|c|c|c|c|c|}
\hline \multicolumn{4}{|c|}{ Glycine } & \multicolumn{3}{|c|}{$\therefore$ L-Alanine } & \multicolumn{3}{|c|}{ L-Valine } & \multicolumn{3}{|c|}{ L-Phenyla lanine } \\
\hline $\begin{array}{l}\text { Percent } \\
\mathrm{T}-\text { Butanol } \\
(\mathrm{v} / \mathrm{v})\end{array}$ & $\operatorname{Ratio}_{1}^{a}$ & $\operatorname{Ratio}_{2}^{b}$ & $\underset{3}{\text { Ratio }}$ & $\operatorname{Ratio}_{1}^{a}$ & $\operatorname{Ratio}_{2}^{b}$ & $\begin{array}{c}\text { Ratio } \\
3\end{array}$ & $\underset{1}{\text { Ratio }}$ & $\underset{2}{\text { Ratio }}$ & $\underset{3}{\operatorname{Ratio}^{c}}$ & $\underset{1}{\text { Ratio }}$ & ${ }_{2}^{\text {Ratio }}$ & $\underset{3}{\text { Ratioc }}$ \\
\hline 0 & 16.0 & - & - & 30.0 & - & - & 110.0 & - & - & 308.0 & - & - \\
\hline 10 & 23.3 & 0.5 & 47.0 & 38.3 & 0.84 & 45.5 & 133.1 & 2.9 & 46.3 & 385.9 & 8.3 & 46.5 \\
\hline 30 & 39.2 & 3.3 & 12.0 & 57.3 & 4.8 & 11.96 & 212.3 & 17.6 & 12.1 & 400.4 & 33.5 & 11.96 \\
\hline 50 & 57.2 & 11.1 & 5.16 & 85.1 & 16.5 & 5.15 & 283.0 & 54.9 & 5.15 & 353.8 & 67.1 & 5.27 \\
\hline 70 & 144.5 & 65.6 & 2.20 & 185.3 & 84.1 & $2: 20$ & 371.3 & 168.1 & 2.21 & 394.8 & 178.7 & 2.21 \\
\hline 90 & 1070 & 1871 & 0.57 & 1069 & 1871 & 0.57 & 595.0 & 1043 & 0.57 & 1069 & 1871 & 0.57 \\
\hline 100 & - & 2499 & - & - & 11110 & - & - & 1470 & - & - & 11110 & - \\
\hline
\end{tabular}

${ }^{a}$ Ratio of water to solute molecules

${ }^{b}$ Ratio of tertiary butanol to solute molecules

${ }^{C_{\text {Ratio }}}$ of water to tertiary butanol molecules per solute molecule 
system components is determined as a function of their density. The number of molecules of the two solvents per amino acid molecule is then calculated by dividing each by the mole fraction of the amino acid. It can be seen that as the number of semi-polar molecules per solute molecule increases, the ratio of water to semi-polar solvent molecules decreases and the solubility of the amino acids, dominated by the charged $\mathcal{O}$-amino carboxylic acid group, decreases. In the pure semi-polar solvents, the four amino acids show a high solvent-solute ratio and a low solubility, and substantiate the assumption that this type of solvent does not have the polar attraction to produce a high solubility in an amino acid dominated by its charged dipole. However, it should be noted that in any given solvent system for any of the amino acids studied, the ratio of water to semipolar' solvent molecules illustrated in column three is essentially the same for a given percent strength. For example, in the methanolwater solvent system, this ratio for each of the amino acids at $10 \%$ $(v / v)$ is 20.2 to 20.6 ; at $30 \%$ it is 5.23 to 5.28 ; at $50 \%$ it is 2.26 to 2.27 ; at $70 \%$ it is .97 ; and at $90 \%$ it is . 25. This substantiates the fact that a given solvent system is composed of a given number of polar and semi-polar molecules and that the amino acid dipole produces a similar effect on a given solvent system regardless of the composition or length of its non-polar portion, and that the relative difference in solubility between amino acids is due to the 
effect of the non-polar portion of the molecule. That these differences in solubility are due to the non-polar portion of the molecule was mentioned by Nozaki, Tanford (27) when they reported that the interaction of an amino acid side chain is independent of the structure to which it is attached in ethanol-water and probably in other solvents as well. The effect of changing a solvent system on the solubility of a single amino acid can be seen if the molar solubility is plotted as a function of increasing percent concentration of the solvents used. In Figures 7 - 9, only four of the solvents are used with isopropanol eliminated since, in most cases, it gave results which did not vary significantly from n-propanol. It would be expected that the polar amino acids would be most soluble in the more polar solvent systems. Using dielectric constant as a measure of polarity, the pure solvents can be arranged in this order of decreasing polarity: methanol, ethanol, n-propanol, and tertiary butanol. These semi-polar solvents in combination with water will produce a series of solvent systems with the same order of decreasing polarity. For example, a.t $30 \%(\mathrm{v} / \mathrm{v})$ of semi-polar solvent-water, the order of decreasing polarity remains methanol-water, ethanol-water, n-propanol-water, and tertiary butanol-water. However, it can be seen in Figure 7 that glycine throughout the concentration scale shows a decreasing solubility in the order of n-propanol, tertiary butanol, ethanol and methanol. As illustrated in Figure 8, the addition of a methyl group to form L-alanine 


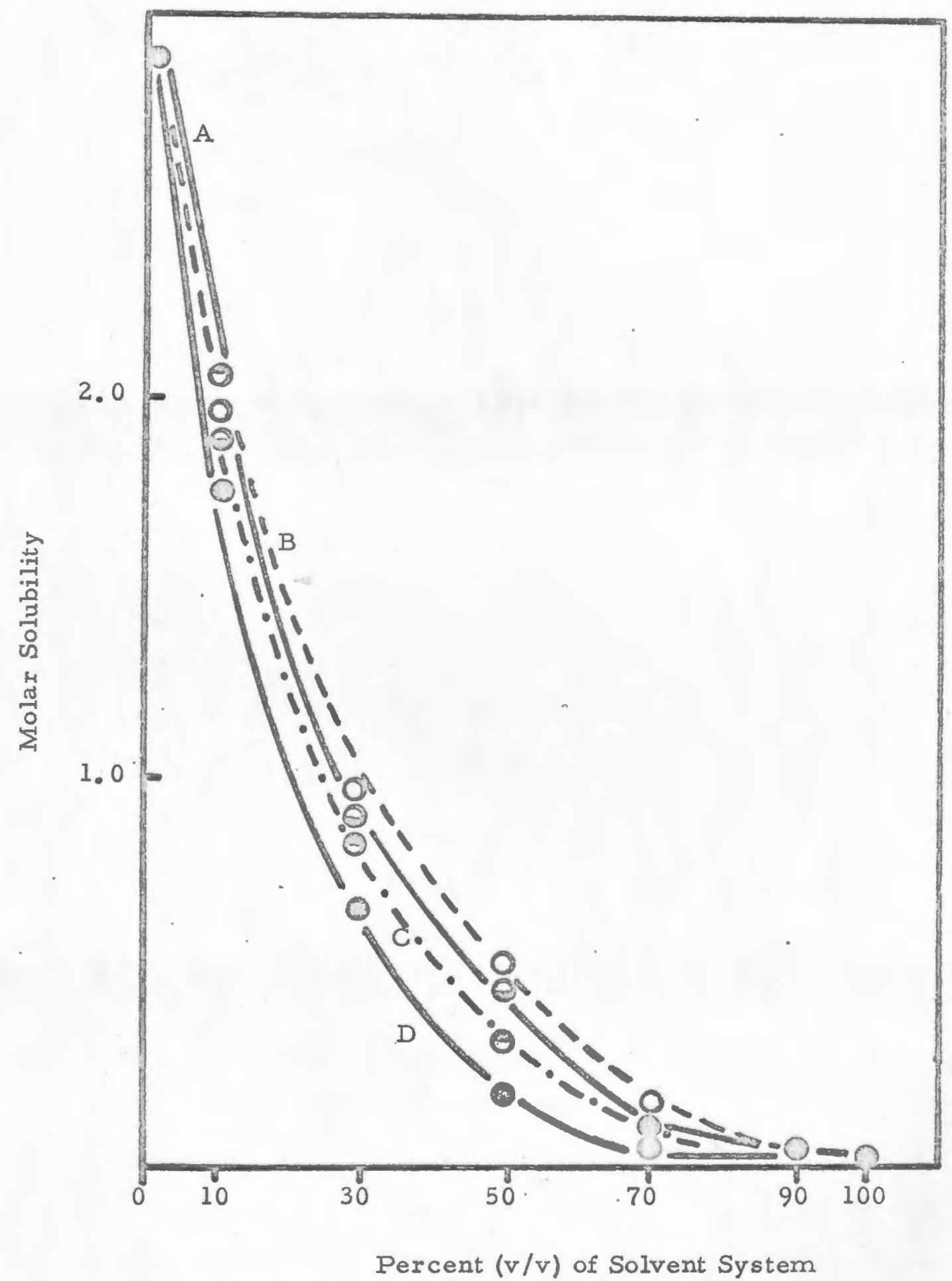

Figure 7. Molar Solubility of Glycine in the Solvent Systems. Curve A - n-Propanol, Curve B - Tertiary-Butanol, Curve C - Ethanol, Curve D - Methanol. 


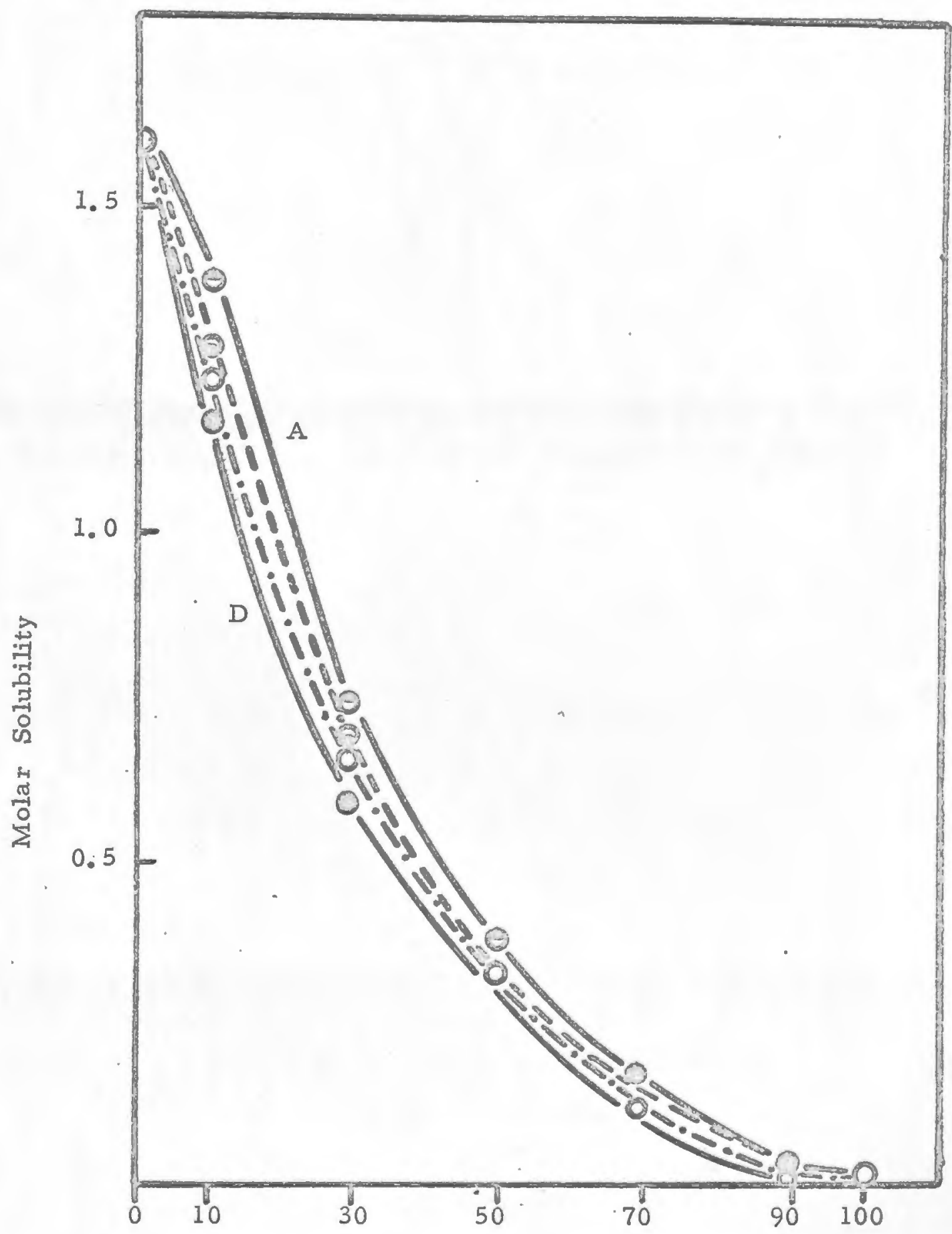

Figure 8. Molar Solubility of L-Alanine in the Solvent Systems. Curves Identified in Descending Order between 10 and 30\% are: Curve A - Methanol, Curve B - Ethanol, Curve C - n-Propanol, Curve D - Tertiary Butanol. 


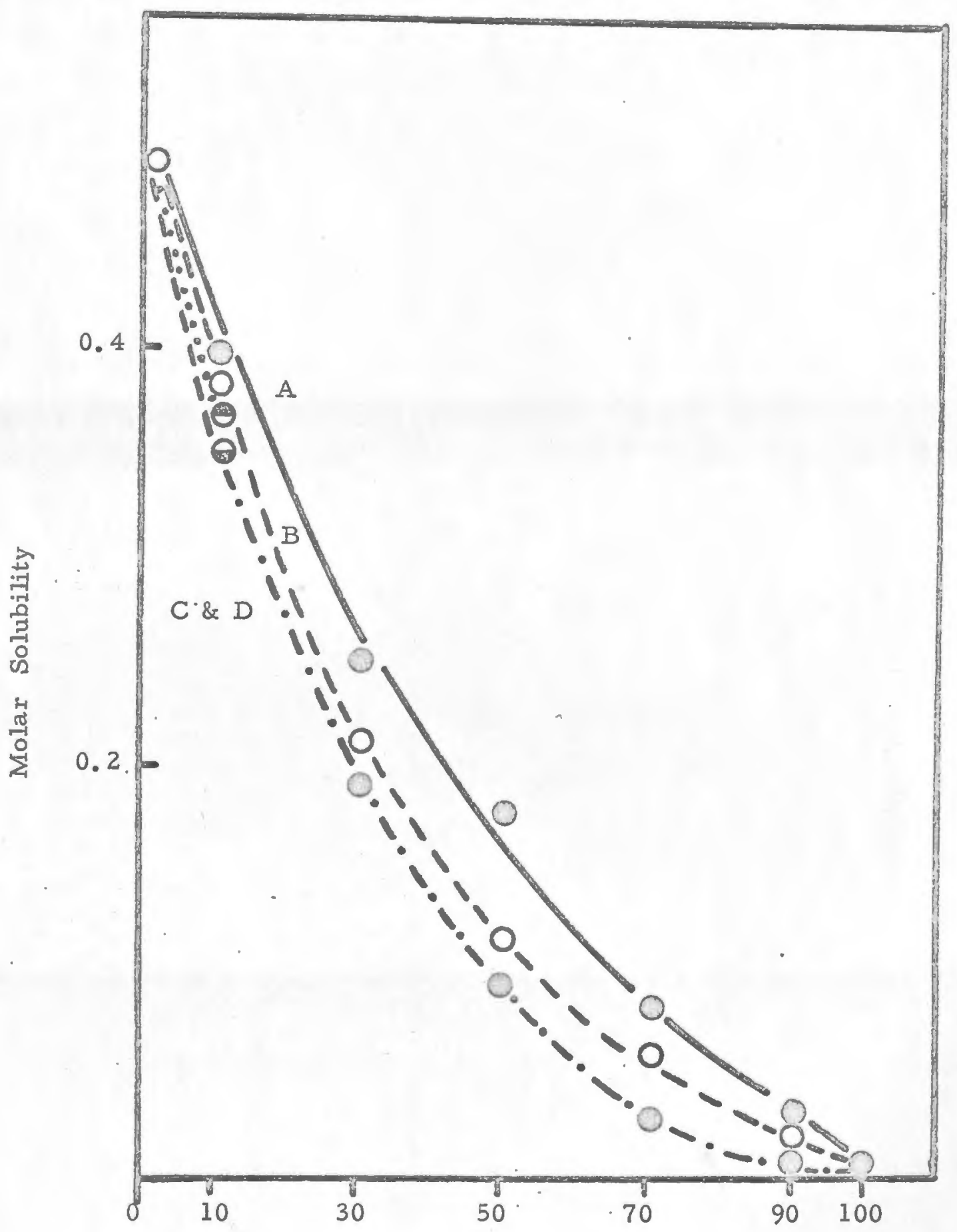

Figure 9. Molar Solubility of L-Valine in the Solvent Systems. Curve A - n-Propanol, Curve B - Methanol, Curve CEthanol, "Curve D - "Tertiary Butanol. 
changes the order of binary solubility to that which was originally expected. In Figure 9, L-valine with an added isopropyl group shows its greatest solubility in n-propanol followed in decreasing order by methanol, ethanol, and tertiary butanol. The order of solubility of L-phenylalanine does not seem to change appreciably with different solvent systems producing a solid line for any illustrations attempted on a scale comparative with Figures $7-9$.

If the order of solubility of glycine is said to illustrate the behavior of the charged $\alpha$-amino carboxylic acid portion of the molecule, this variation in the order of solubility as methyl, isopropyl, and methyl-phen groups were added serves to further substantiate the independent interactions of each of the non-polar side chains.

The variation of the solvent systems and the effect on the solubility of an amino acid throughout the concentration spectrum can be further illustrated by generating the polynomial regression for each solvent. This equation of the line can be computed using a standard IBM program (28) for an orthogonal polynomial regression. By designating the molar solubility as the dependent variable and the percent strength of the alcoholic solution as the independent variable, the polynomial equation of the standard form $Y=A_{0}+A_{1} X+A_{2} X^{2}+$ $A_{3} x^{3}+\ldots \ldots \ldots A_{n} X^{n}$ can be computed. (See Appendix I) The purpose of generating the equations was to illustrate the relationship between the solubility profiles of an amino acid in each of the solvent 
systems used.

Tables $14-17$ show the effecin inch of the ansino acids in the five solvent systems used in the form of a second degree equaion. The second degree polynomial ecuation was considered mosi representative since the sum of the squares of tine deviation about the rugression in the analysis of variants showed little inprovenzent when the thinc degree or higher polynomial equation was calculated. The Y intercopt in each table is representative of the average solubility in a pure acueous solvent. The coefficients of the $X$ and $X^{2}$ terms derine the curve of ilie line. It was not expected that the polynomial regression equation wouid precisely define the solubility of the amino acids. In Tabie $1 \neq$, the proximity of the $Y$ intercept values which range from 2.65204 to $2.791 \div 8$ with a true solubility of $2.9 \mathrm{M}$. in pure water can be secu. The $X$ and $X^{2}$ values also show a similarity. In Tabie 15, L-aianine shows a range of 1.57939 to 1.66390 in the Y intercepis with a irue aqueous solubility of $1.63 \mathrm{~N}$. A range of only 0.08455 as compared to the range of 0.13944 for glycine, thereby showing a closer approximation of the true solubility. This is expected since the average of the sun of the squares of tise deviation about the regression for L-alanine in all solvents is only 0.00538 as compared to 0.11104 for glycine. The sum of the squares of the deviation about the regression is a measure of the closeness of fit between the data points calculated from the computed poiynomial equation and those data points observed experimentally. (29) Ir Tables 16 axd 17 the computed polynomiai 


\section{TABIE $1 \div$}

TIE POLYNOMIAL REGRESSION DAIA GENERATED FROM

THE MOLAR SOLUBILIFY OF GLYCINE AS A FUNOTION

OF TIE PERCENT STRENGTH OF THE SOLVENT SYSTEN

\begin{tabular}{|c|c|c|c|}
\hline \multirow[t]{2}{*}{ Solvent System ${ }^{a}$} & \multirow[t]{2}{*}{$Y$ Intercepi } & \multicolumn{2}{|c|}{ Coefficients } \\
\hline & & $X$ & $x^{2}$ \\
\hline ivietianol & 2.6520 & -0.0743 & 0.0005 \\
\hline Etrianol & 2.7823 & -0.0738 & 0.0005 \\
\hline n-Propanol & 2.7591 & -0.0065 & 0.000 .1 \\
\hline Isopropanol & 2.7915 & -0.0721 & 0.0005 \\
\hline $\begin{array}{r}\text { Tertiary } \\
\text { Dutunol }\end{array}$ & 2.7303 & -0.0676 & $0.000 \div$ \\
\hline
\end{tabular}

a Volar solubility values oi Glycinu in 0 to $100 \%(\mathrm{v} / \mathrm{v})$ of each solvent system were used to generate the poiynomial equation 
TABLE 15.

THE POLYNOMIAL REGRESSION DATA GENERATED FROM

THE MOLAR SOLUBIIITY OF L-ALANINE AS A FUNCTION

OF THE PERCENT STRENGTH OF THE SOLVENT SYSTEM

\begin{tabular}{|c|c|c|c|}
\hline \multirow[t]{2}{*}{ Solvent System ${ }^{a}$} & \multirow[t]{2}{*}{ Y Intercept } & \multicolumn{2}{|c|}{ Coefficients } \\
\hline & & $\mathrm{x}$ & $x^{2}$ \\
\hline Methanol & 1.6640 & -0.0354 & 0.0002 \\
\hline Ethanol & 1.6238 & -0.0366 & 0.0002 \\
\hline n-Propanol & 1.5881 & -0.0347 & 0.0002 \\
\hline Isopropanol & 1.6019 & -0.0378 & 0.0002 \\
\hline $\begin{array}{r}\text { Tertiary } \\
\text { butanol }\end{array}$ & 1. 5794 & -0.0363 & 0.0002 \\
\hline
\end{tabular}


TABLE 16.

THE POLYNOMIAL REGRESSION DATA GENERATED FROM

THE MOLAR SOLUBILITY OF L-VALINE AS A FUNCTION

OF THE PERCENT STRENGTH OF THE SOLVENT SYSTEM

\begin{tabular}{llcc}
\hline \hline Solvent System & \\
& Y Intercept & \multicolumn{2}{c}{ Coefficients } \\
\hline Methanol & 0.4581 & -0.0089 & 0.00005 \\
Ethanol & 0.4629 & -0.0104 & 0.00006 \\
n-Propanol & 0.4732 & -0.0080 & 0.00003 \\
$\begin{array}{l}\text { Isopropanol } \\
\text { Tertiary } \\
\text { butanol }\end{array}$ & 0.4592 & -0.0104 & 0.00006 \\
\hline
\end{tabular}

${ }^{a}$ Molar solubility values of L-valine in 0 to $100 \%(v / v)$ of each solvent system were used to generate the polynomial equation. 
TABLE 17.

THE POLYNOMIAL REGRESSION DATA GENERATED FROM THE MOLAR SOLUBILITY OF L-PHENYLALANINE AS A FUNCTION OF THE PERCENT STRENGTH OF THE SOLVENT SYSTEM

\begin{tabular}{|c|c|c|c|}
\hline \multirow[t]{2}{*}{ Solvent System ${ }^{a}$} & \multirow[t]{2}{*}{ Y Intercept } & \multicolumn{2}{|c|}{ Coefficients } \\
\hline & & $x$ & $x^{2}$ \\
\hline Methanol & 0.1646 & -0.0019 & 0.00001 \\
\hline Ethanol & 0.1659 & -0.0022 & 0.00001 \\
\hline n-Propanol & 0.1602 & -0.0021 & 0.00001 \\
\hline Isopropanol & 0.1581 & -0.0020 & 0.00001 \\
\hline $\begin{array}{c}\text { Tertiary } \\
\text { butanol }\end{array}$ & .0 .1609 & -0.0022 & 0.00001 \\
\hline
\end{tabular}


equations for L-valine and L-phenylalanine show an even closer approximation to the experimental points. L-valine shows a range of only 0.01548 for a solubility of $0.474 \mathrm{M}$. and an average sum of squares of the deviation about the regression of 0.00135 . L-phenylalanine has a range of only 0.00788 between its high and low $Y$ intercepts with a true solubility of $0.172 \mathrm{M}$. and an average sum of the squares of the deviation about the regression of only 0.00055 .

The closeness of the Yintercepts and the similarity between the coefficients of the $X$ and $X^{2}$ terms seem to indicate the existence of a closely related family of curves when the solubilities of each amino acid in the five solvents are compared. The differences between the curves are quite regular and a function of both dielectric constant of each solvent system and the individual interaction of the amino acid with each solvent. 
The addition of acid or base to an amino acid in aqueous

solution at the point of neutral solubility produces a change in the species present. The dissociation of the amino acid illustrated below shows the species present and the two dissociation constants, $K_{1}$ and $K_{2} \cdot(30)$

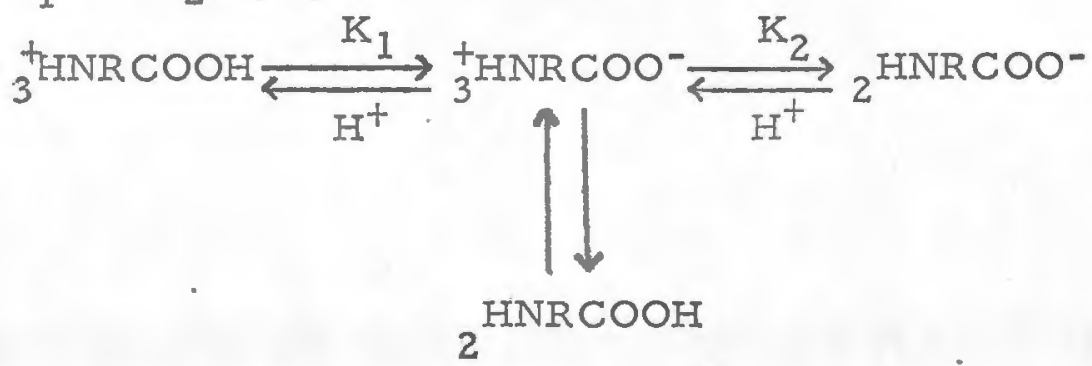

$$
\mathrm{K}_{1}=\frac{(\mathrm{H})^{+}\left({ }_{3}^{+} \mathrm{HNRCOO}^{-}\right)}{\left(_{3}^{+} \mathrm{HNRCOOH}\right)} \quad \mathrm{K}_{2}=\frac{(\mathrm{H})^{+}\left(\mathrm{HNRCOO}_{2}^{-}\right)}{\left({ }_{3}^{+} \mathrm{HNRCOO}^{-}\right)}
$$

Thus it can be seen that in a neutral aqueous solution the zwitterion of the amino acid exists in equilibrium with the uncharged species in a specific ratio as described in the previous section. The addition of acid to the neutral solution will produce the cationic species in proportion to the first dissociation constant, $K_{1}$. Conversely, the addition of base to a neutral aqueous solution produces the anionic species as a function of the $K_{2} \cdot(31)$

The isoelectric point has been defined as the pH value at which the average net charge of the dipolar molecule is equal to zero. (32) Using the two dissociation constants, $\mathrm{K}_{1}$ and $\mathrm{K}_{2}$, the isoelectric point has been shown to be $\mathrm{pH}_{I}=\left(\mathrm{pK}_{1}+\mathrm{pK}_{2}\right) / 2$ in the amino acids studied. (33) However, if the solubility is plotted as a function of the 
$\mathrm{pH}$, illustrated in Figure 10, the presence of an invariant band of similar solubility for a range of $\mathrm{pH}$ variation on either side of the calculated isoelectric point is seen for each amino acid. This is followed by a rapid increase in solubility as the $\mathrm{pH}$ is increased or decreased on either side of the invariant band. The presence of an isoelectric band rather than a single isoelectric point was mentioned by Cohn and Edsall. (34,: 35$)$ They postulated that for a simple amino . acid whose $K_{1}$ and $K_{2}$ are sufficiently separated an isoelectric band is produced throughout which the concentration of the cation and anion is very low and the dipolar species will dominate.

In Table 18 the effect of adding acid and base on the total solubility of the four amino acids in aqueous solution is illustrated. The solubility range of each amino acid was separated into two portions, that influenced by acid addition and that influenced by base addition, and a least squares computer analysis was calculated for each part. (See Appendix II) In all cases the correlation coefficient was 0.80 or greater. The moles of acid or base added was designated as the independent variable; and the total solubility of the amino acid as the dependent variable. Table 19 shows the calculated first degree equation in the form of $\mathrm{Y}=\mathrm{mX}+\mathrm{b}$ for moles of $\mathrm{HCl}$ added. The $\mathrm{Y}$ intercept indicated the initial solubility of the amino acid and closely approximated the experimentally observed values with an average error of less than four percent. The slopes of the lines show an increase inversely proportional to the solubility of the amino acids. 


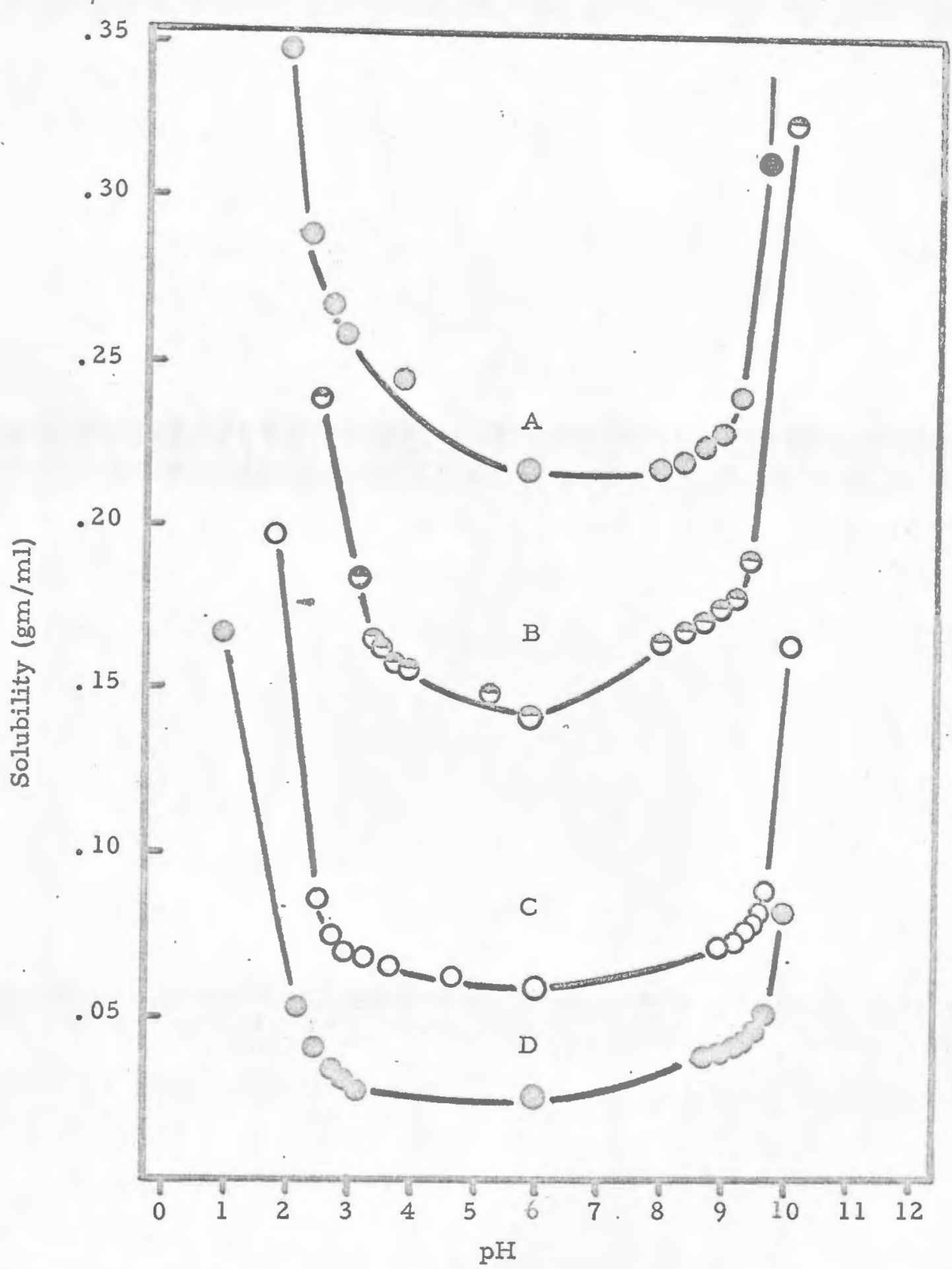

Figure 10. The Change in Aqueous Solubility of the Amino Acids as a Function of $\mathrm{pH}$. Curve A - Glycine, Curve B - L-Alanine, Curve C - L-Valine, Curve D - L-Phenylalanine. 
TABLE 18.

THE EFFECT OF ADDING ACID OR BASE ON THE TOTAL SOLUBILITY OF THE AMINO ACIDS, IN AQUEOUS SYSTEMS ${ }^{a}$

\begin{tabular}{|c|c|c|c|c|c|}
\hline & cine & & L- & lanine & \\
\hline $\begin{array}{l}\text { Total Acid or } \\
\text { Base Added } \\
\text { (moles) }\end{array}$ & $\begin{array}{c}\text { Solubility } \\
(\mathrm{gm} / \mathrm{ml})\end{array}$ & $\mathrm{pH}$ & $\begin{array}{l}\text { Total Acid or } \\
\text { Base Added } \\
\text { (moles) }\end{array}$ & $\begin{array}{c}\text { Solubility } \\
(\mathrm{gm} / \mathrm{ml})\end{array}$ & $\mathrm{pH}$ \\
\hline$\overline{-}$ & - & - & 0.261 & 0.1780 & 3.05 \\
\hline 1.090 & 0.3614 & 2.40 & 0.181 & 0.1652 & 3.20 \\
\hline 0.940 & 0.2895 & 2.60 & .0 .151 & 0.1645 & 3.40 \\
\hline 0.640 & 0.2661 & 2.75 & 0.111 & 0.1587 & 3.60 \\
\hline 0.490 & 0.2635 & 2.85 & 0.081 & 0.1575 & 3.85 \\
\hline 0.192 & 0.2556 & 3.60 & 0.031 & 0.1564 & 5.40 \\
\hline neutral & 0.2178 & 6.00 & neutral & 0.1450 & 6.00 \\
\hline 0.321 & 0.2190 & 8.20 & 0.105 & 0.1721 & 8.10 \\
\hline 0.430 & 0.2230 & 8.50 & 0.155 & 0.1741 & 8.40 \\
\hline 0.540 & 0.2266 & 8.70 & 0.225 & 0.1756 & 8.70 \\
\hline 0.651 & 0.2325 & 8.90 & 0.275 & 0.1766 & 8.90 \\
\hline 0.760 & 0.2432 & 9.10 & 0.345 & 0.1786 & 9.10 \\
\hline 0.980 & 0.3088 & 9.40 & 0.395 & 0.1853 & 9.20 \\
\hline
\end{tabular}

${ }^{2}$ Each solubility value is the average of at least 3 determinations 
TABLE 18--Continued

\begin{tabular}{|c|c|c|c|c|c|}
\hline \multicolumn{3}{|c|}{ L-Valine } & \multicolumn{3}{|c|}{ L-Phenylalanine } \\
\hline $\begin{array}{l}\text { Total Acid or } \\
\text { Base Added } \\
\text { (moles) }\end{array}$ & $\begin{array}{r}\text { Solubility } \\
(\mathrm{gm} / \mathrm{ml})\end{array}$ & $\mathrm{pH}$ & $\begin{array}{l}\text { Total Acid or } \\
\text { Base Added } \\
\text { (moles) }\end{array}$ & $\begin{array}{r}\text { Solubility } \\
(\mathrm{gm} / \mathrm{ml})\end{array}$ & $\mathrm{pH}$ \\
\hline 0.235 & 0.0894 & 2.35 & 0.293 & 0.1706 & 1.15 \\
\hline 0.155 & 0.0806 & 2.60 & 0.119 & 0.0540 & 2.25 \\
\hline 0.125. & 0.0783 & 2.70 & 0.099 & 0.0478 & 2.30 \\
\hline 0.085 & 0.0736 & 3.05 & 0.089 & 0.0455 & 2.40 \\
\hline 0.055 & 0.0707 & 3.35 & 0.059 & 0.0411 & 2.65 \\
\hline 0.005 & 0.0677 & 4.60 & 0.029 & 0.0368 & 3.00 \\
\hline neutral & 0.0559 & 6.10 & neutral & 0.0274 & 6.00 \\
\hline 0.167 & 0.0826 & 8.90 & 0.083 & 0.0467 & 8.65 \\
\hline 0.217 & 0.0854 & 9.10 & 0.113 & 0.0495 & 8.80 \\
\hline 0.257 & 0.0906 & 9.30 & 0.123 & 0.0505 & 8.90 \\
\hline 0.307 & 0.0951 & 9.40 & 0.133 & 0.0519 & 9.00 \\
\hline 0.337 & 0.0967 & 9.45 & 0.163 & 0.0560 & 9.15 \\
\hline 0.357 & 0.0983 & 9.50 & 0.183 & 0.0603 & 9.20 \\
\hline
\end{tabular}


TABIE 19.

THE EFFECT OF ADDING ACID ON THE TOTAL AQUEOUS SOLUBILITY OF THE AMINO ACIDS ${ }^{a}$

\begin{tabular}{lccc}
\hline \multicolumn{1}{c}{ Amino Acid } & Y Intercept & Slope & $\begin{array}{c}\text { Correlation } \\
\text { Coefficient }\end{array}$ \\
\hline Glycine & 0.2182 & 0.1026 & 0.8967 \\
L-Alanine & 0.1482 & 0.1078 & 0.9620 \\
L-Valine & 0.0624 & 0.1195 & 0.9442 \\
L-Phenylalanine & 0.0286 & 0.2042 & 0.9871 \\
\hline Moles of HCl as a function of amino acid solubility (gm/ml)
\end{tabular}


Glycine and L-alanine show a similar slope. L-valine displayed an increase of approximately 13 percent over the first two amino acids. L-phenylalanine showed an increase in slope almost twice that of glycine. The first degree equations representing addition of $\mathrm{NaOH}$ are shown in Table 20. Here the same general trend is seen as was seen in the case of acid addition. The error in approximating the initial solubility at the $Y$ intercept is on the average less than 6 percent. The glycine and L-alanine show similar slopes with the L-alanine just slightly lower than the glycine. The slopes for L-valine and L-phenylalanine both show an increase over the first two amino acids similar to that produced by acid addition. It would seem that the slope which represents the increase in total solubility as a function of acid or base added is dependent on the structure of the amino acid. As the nonpolar-polar ratio increases the ease of salt formation is enhanced.

In tracing the total solubility of the amino acids as a function of $\mathrm{pH}$ and as a function of the acid or base added, it is logical to consider the composition at those points above and below the isoelectric band. It would seem that the total solubility $\left(C_{T}\right)$ is the sum of the solubility due to the zwitterions $\left(C_{A}\right)$ and that due to the anion or cation which would form an associated salt $\left(C_{S}\right)$ with the acid or base added. To prove this postulation the equations:

$$
\mathrm{pH}=\log \left(\mathrm{C}_{\mathrm{A}} / \mathrm{C}_{\mathrm{S}}\right)+\mathrm{pK} \mathrm{K}_{1}
$$


TABLE 20 .

THE EFFECT OF ADDING BASE ON THE TOTAL AQUEOUS SOLUBILITY OF THE AMINO ACIDS ${ }^{a}$

\begin{tabular}{lccc}
\hline Amino Acid & Y Intercept & Slope & $\begin{array}{c}\text { Correlation } \\
\text { Coefficient }\end{array}$ \\
\hline Glycine & 0.1961 & 0.0809 & 0.7973 \\
L-Alanine & 0.1554 & 0.0800 & 0.8681 \\
L-Valine & 0.0587 & 0.1178 & 0.9844 \\
L-Phenylalanine & 0.0291 & 0.1738 & 0.9874 \\
\hline
\end{tabular}

${ }^{a}$ Moles of $\mathrm{NaOH}$ as a function of amino acid solubility $(\mathrm{gm} / \mathrm{ml})$ 


$$
\mathrm{pH}=\log \left(\mathrm{C}_{\mathrm{S}} / \mathrm{C}_{\mathrm{A}}\right)+\mathrm{pK}_{2}
$$

were derived from the appropriate dissociation constant equations previously described. The solubility in the neutral solution was subtracted from the total solubility and this value considered to be equal to the salt formed. The $C_{A}$ and $C_{S}$ were converted to molar solubility. In all calculations of salt molarity it was as sumed that the amino acid combined in a mole to mole ratio with the acid ox base added. The half hydrochloride salts of glycine and L-alanine mentioned in the literature (36) were considered not to form. The log of the ratios of $\left(C_{A} / C_{S}\right)$ and $\left(C_{S} / C_{A}\right)$ were considered to be the independent variables, and the $\mathrm{pH}$ as the dependent variable. Using the computer program described in Appendix II, the first degree equation and correlation coefficients were calculated. In Tables 21 and 22 the results of this calculation are shown. While the $Y$ intercepts show some deviation from the literature values (37) for the $\mathrm{pK}_{1}$ and $\mathrm{pK}_{2}$, the correlation coefficients with a range of 0.8733 to 0.9908 indicate a very high adherance to the first degree equation in all cases. This shows that the initial assumptions are true: that the total solubility of an amino acid in aqueous solution is equal to the sum of the solubility of the ampholyte plus. the salt formed, and that the single hydrochloride salts of the amino acids are formed.

The solubility variation when acid or base was added to separate samples of each amino acid in the series of decreasing polarity for 
TABLE 21 .

FIRST DEGREE RELATIONSHIP BETWEEN pḦ

AND LOG $\left(\mathrm{C}_{\mathrm{A}} / \mathrm{C}_{\mathrm{S}}\right)$ FOR ACID ADDITION

\begin{tabular}{lccc}
\hline \multicolumn{1}{c}{ Amino Acid } & Y Intercept & Slope & $\begin{array}{l}\text { Correlation } \\
\text { Coefficient }\end{array}$ \\
\hline Glycine & 2.09 & 0.843 & 0.976 \\
L-Alanine & 1.52 & 1.824 & 0.938 \\
L-Valine & 1.17 & 3.284 & 0.943 \\
L-Phenylalanine & 1.97 & 1.900 & 0.972 \\
\hline
\end{tabular}


TABLE 22 .

FIRST DEGREE RELATIONSHIP BETWEEN pH

AND LOG $\left(C_{S} / C_{A}\right)$ FOR BASE ADDITION

\begin{tabular}{lccc}
\hline Amino Acid & Y Intercept & Slope & $\begin{array}{l}\text { Correlation } \\
\text { Coefficient }\end{array}$ \\
\hline Glycine & 9.83 & 0.765 & 0.999 \\
L-Alanine & 9.70 & 3.732 & 0.887 \\
L-Valine & 9.91 & 2.182 & 0.996 \\
L-Phenylalanine & 9.17 & 2.294 & 0.965 \\
\hline
\end{tabular}


$10 \%, 30 \%, 50 \%, 70 \%, 90 \%$, and $100 \%(\mathrm{v} / \mathrm{v})$ of methanol, ethanol, n-propanol, isopropanol, and tertiary butanol was similar to that seen previously in the pure aqueous solvent systems. The minimum solubility occurred in the neutral solution with the addition of acid or base causing an increase in total solubility. Tables $23-27$ are representative of the effect of $\mathrm{pH}^{\prime}$ on the total solubility of glycine in each of the solvent systems. Figures $11-15$ illustrate more clearly the relative solubility between the amino acids and the variation in solubility for each of the amino acids in each of the pure semi-polar solvents. There is an absence of the wide isoelectric band of invariant solubility that was seen in pure aqueous systems, and a distinct increase in total solubility is seen for the change in $\mathrm{pH}^{3}$ away from the neutral solubility point. Further, the increase in total solubility in the semi-polar solvents seems to reach a higher magnitude per amount of acid or base added as the polarity of the solvent system is decreased. Using the seven ethanol-water solvent systems in combination with the four most soluable amino acids as an example, the increase in total solubility as a function of acid or base additions as well as decreasing polarity is seen in Figures 16 19. Here the ratio of the total solubility (S) to the solubility at the neutral point $\left(S_{0}\right)$ is plotted as a function of grams of acid or base added. The first three strengths, 0,10 , and $30 \%(\mathrm{v} / \mathrm{v})$, merge as one straight line. Only L-phenylalanine shows any discernable difference between the linear increase at these percentage strengths. 
TABLE 23.

THE EFFECT OF ADDING ACID OR BASE ON THE SOLUBILITY OF GLYCINE IN METHANOL-WATER SOLVENT SYSTEMS

\begin{tabular}{|c|c|c|c|c|c|c|c|c|c|c|c|c|}
\hline $\begin{array}{l}\text { Total Acid } \\
\text { or Base }\end{array}$ & \multicolumn{2}{|c|}{$10 \%(\mathrm{v} / \mathrm{v})$} & \multicolumn{2}{|c|}{$30 \%(v / v)$} & \multicolumn{2}{|c|}{$50 \%(v / v)}$. & \multicolumn{2}{|c|}{$70 \%(\mathrm{v} / \dot{\mathrm{v}})$} & \multicolumn{2}{|c|}{$90 \%(v / v)$} & \multicolumn{2}{|c|}{$100 \%(\mathrm{v} / \mathrm{v})$} \\
\hline & $\begin{array}{l}\text { Solubili } \\
(\mathrm{gm} / \mathrm{m})\end{array}$ & $\mathrm{pH}^{\prime}$ & $\begin{array}{l}\text { Solubili } \\
\mathrm{(gm} / \mathrm{m} \mathrm{l}\end{array}$ & $\mathrm{pH}^{\prime}$ & $\begin{array}{l}\text { Solubility } \\
(\mathrm{gm} / \mathrm{ml})\end{array}$ & $\mathrm{pH}^{\prime}$ & $\begin{array}{l}\text { Solubilit } \\
(\mathrm{gm} / \mathrm{ml})\end{array}$ & $\mathrm{pH}^{\prime}$ & $\begin{array}{l}\text { Solubility } \\
(\mathrm{gm} / \mathrm{ml})\end{array}$ & $\mathrm{pH}$ & $\begin{array}{l}\text { Solubility } \\
(\mathrm{gm} / \mathrm{ml})\end{array}$ & $\mathrm{pH}$ \\
\hline .282 & .2121 & 3.2 & .1160 & 3.3 & .0789 & 3. 1 & .0476 & 3.3 & .0278 & 2.4 & .0216 & 2.4 \\
\hline .047 & .1462 & 4.2 & .0622 & 4.1 & .0231 & 3.7 & .0077 & 3.7 & .0075 & 3.1 & .0057 & 3.2 \\
\hline neutral point & .1308 & 6.4 & .0494 & 6.6 & .0159 & 6.5 & .0076 & 6.6 & .0016 & 6.6 & .0009 & 7.1 \\
\hline .103 & .1575 & 8.9 & .0720 & 9.0 & .0337 & 9.5 & .0183 & 9.4 & .0151 & 9.2 & .0115 & 9.7 \\
\hline
\end{tabular}


TABLE 24:

THE EFFECT OF ADDING ACID OR BASE ON THE SOLUBILITY OF GLYCINE IN ETHANOL-WATER SOLVENT SYSTEMS

\begin{tabular}{|c|c|c|c|c|c|c|c|c|c|c|c|c|}
\hline \multirow[t]{2}{*}{$\begin{array}{l}\text { Total Acid } \\
\text { or Base } \\
\text { Added (gms.) }\end{array}$} & \multicolumn{2}{|c|}{$10 \%(\mathrm{v} / \mathrm{v})$} & \multicolumn{2}{|c|}{$30 \%(\mathrm{v} / \mathrm{v})$} & \multicolumn{2}{|c|}{$50 \%(v / v)$} & \multicolumn{2}{|c|}{$70 \%(v / v)$} & \multicolumn{2}{|l|}{$90 \%(\mathrm{v} / \mathrm{v})$} & \multicolumn{2}{|c|}{$100 \%(\mathrm{v} / \mathrm{v})$} \\
\hline & $\begin{array}{l}\text { Solubilit } \\
(\mathrm{gm} / \mathrm{ml})\end{array}$ & $\mathrm{pH}$ & $\begin{array}{l}\text { Solubility } \\
(\mathrm{gm} / \mathrm{ml})\end{array}$ & $\mathrm{pH}^{\prime}$ & $\begin{array}{l}\text { Solubility } \\
(\mathrm{gm} / \mathrm{ml})\end{array}$ & $\mathrm{pH}^{\prime}$ & $\begin{array}{l}\text { Solubility } \\
(\mathrm{gm} / \mathrm{ml})\end{array}$ & $\mathrm{pH}^{\prime}$ & $\begin{array}{l}\text { Solubility } \\
(\mathrm{gm} / \mathrm{ml})\end{array}$ & $\mathrm{pH}^{\prime}$ & $\begin{array}{l}\text { Solubilit } \\
(\mathrm{gm} / \mathrm{ml})\end{array}$ & $\mathrm{pH}^{\prime}$ \\
\hline .354 & .1874 & 3.6 & .1082 & 3.5 & .0561 & 3.2 & .0416 & 2.9 & .0291 & 2.0 & .0073 & 2.0 \\
\hline .118 & .1672 & 4.1 & .0760 & 3.9 & .0309 & 3.8 & .0284 & 3.5 & .0076 & 3.0 & .0022 & 2.8 \\
\hline .059 & .1576 & 4.8 & .0657 & 4.4 & .0263 & 4.2 & .0101 & 3.9 & .0042 & 3.4 & .0014 & 2.9 \\
\hline neutral point & .1521 & 6.4 & .0609 & 6.2 & .0222 & 6.3 & .0065 & 6.6 & .0010 & 6.7 & .0002 & 7.1 \\
\hline .096 & .1588 & 8.0 & .0689 & 8.3 & .0287 & 8.8 & .0121 & 9.4 & .0073 & 9.7 & .0049 & 9.5 \\
\hline .192 & .1735 & 8.5 & .0830 & 8.8 & .0486 & 9.2 & .0355 & 9.5 & .0116 & 9.7 & .0094 & 9.3 \\
\hline .384 & .1988 & 8.8 & .1159 & 9.2 & .0631 & 9.5 & .0456 & 9.7 & .0326 & 9.7 & .0123 & 9.5 \\
\hline
\end{tabular}


TABLE 25.

THE EFFECT OF ADDING ACID OR BASE ON THE SOLUBILITY OF GLYCINE

IN n-PROPANOL-WATER SOLVENT SYSTEMS

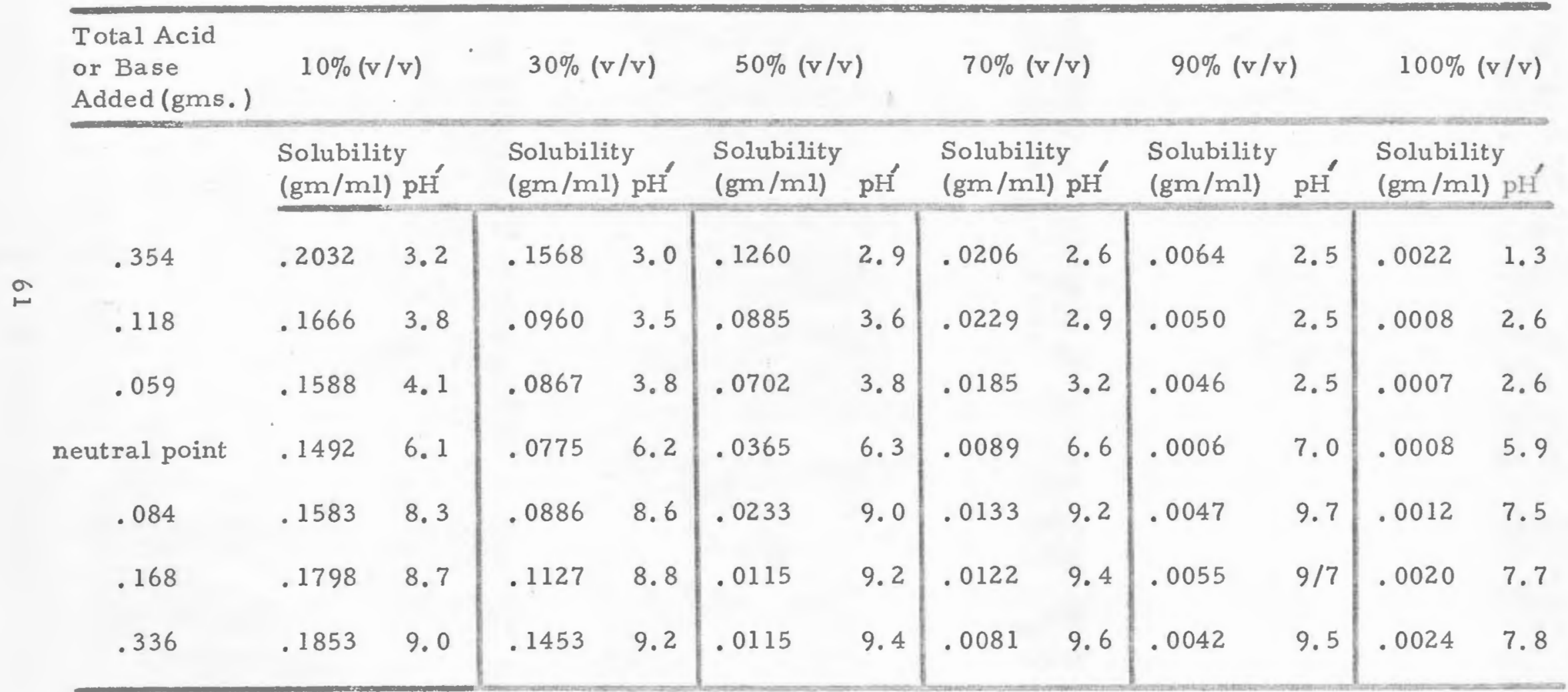


TABLE 26.

THE EFFECT OF ADDING ACID OR BASE ON THE SOLUBILITY OF GLYCINE IN iso-PROPANOL-WATER SOLVENT SYSTEMS

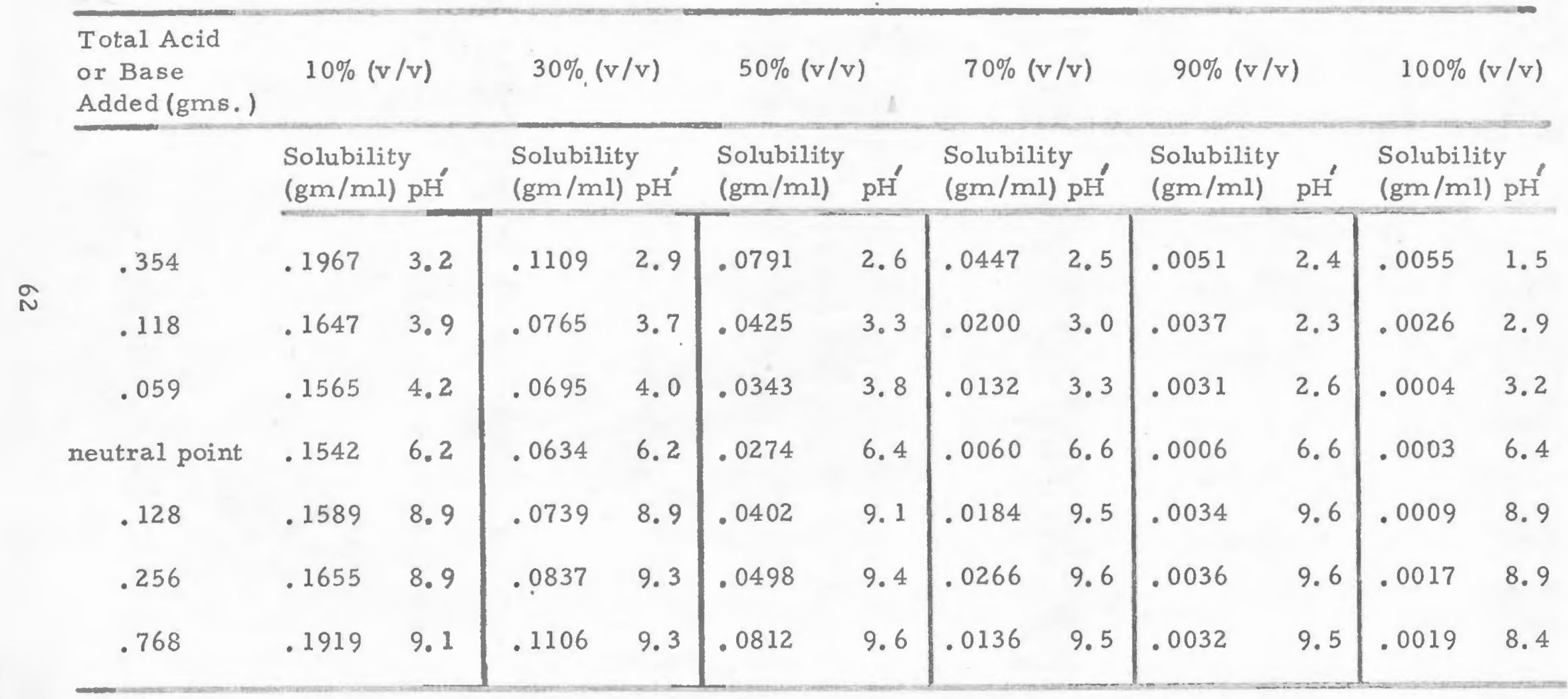


TABLE 27.

THE EFFECT OF ADDING ACID OR BASE ON THE SOLUBILITY OF GLYCINE IN TERTIARY-BUTANOL-WATER SOLVENT SYSTEMS

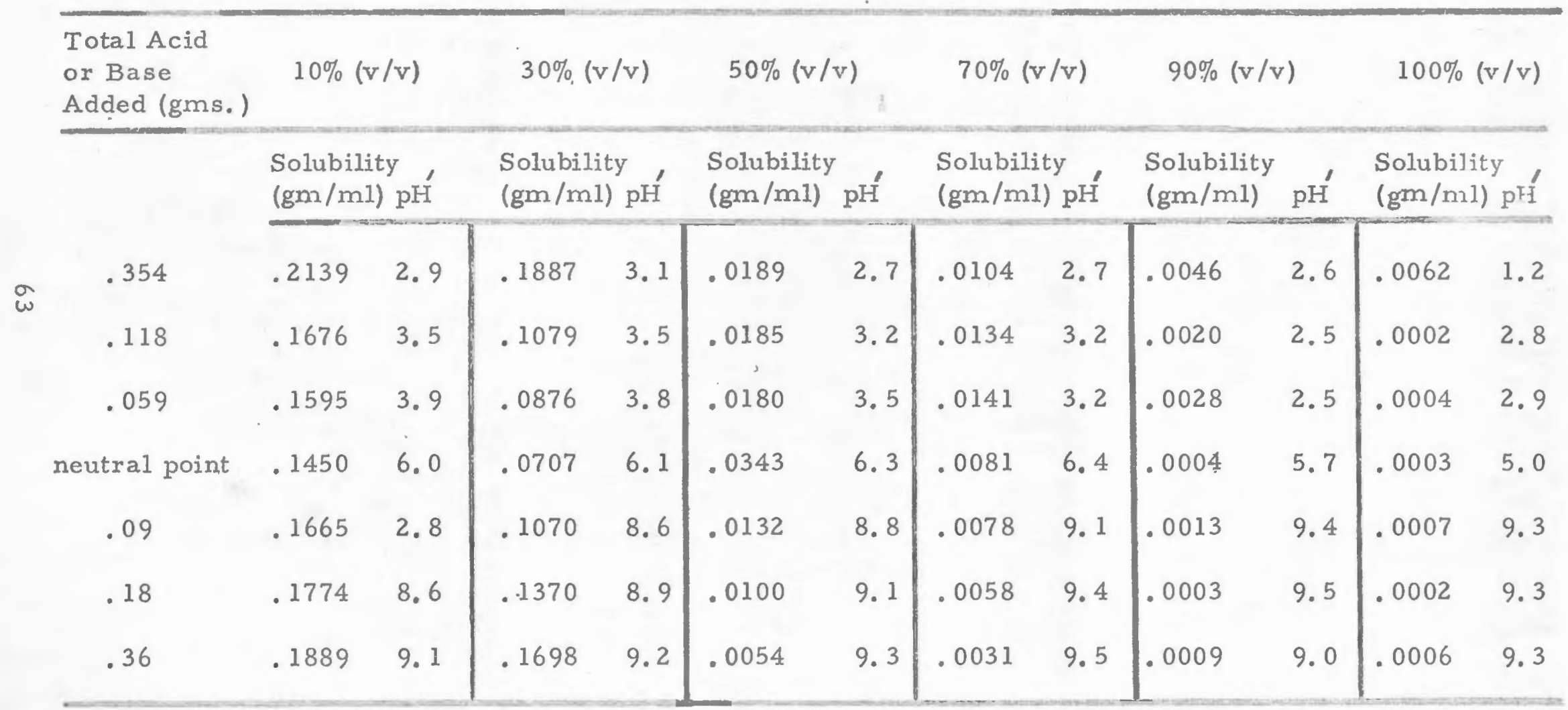




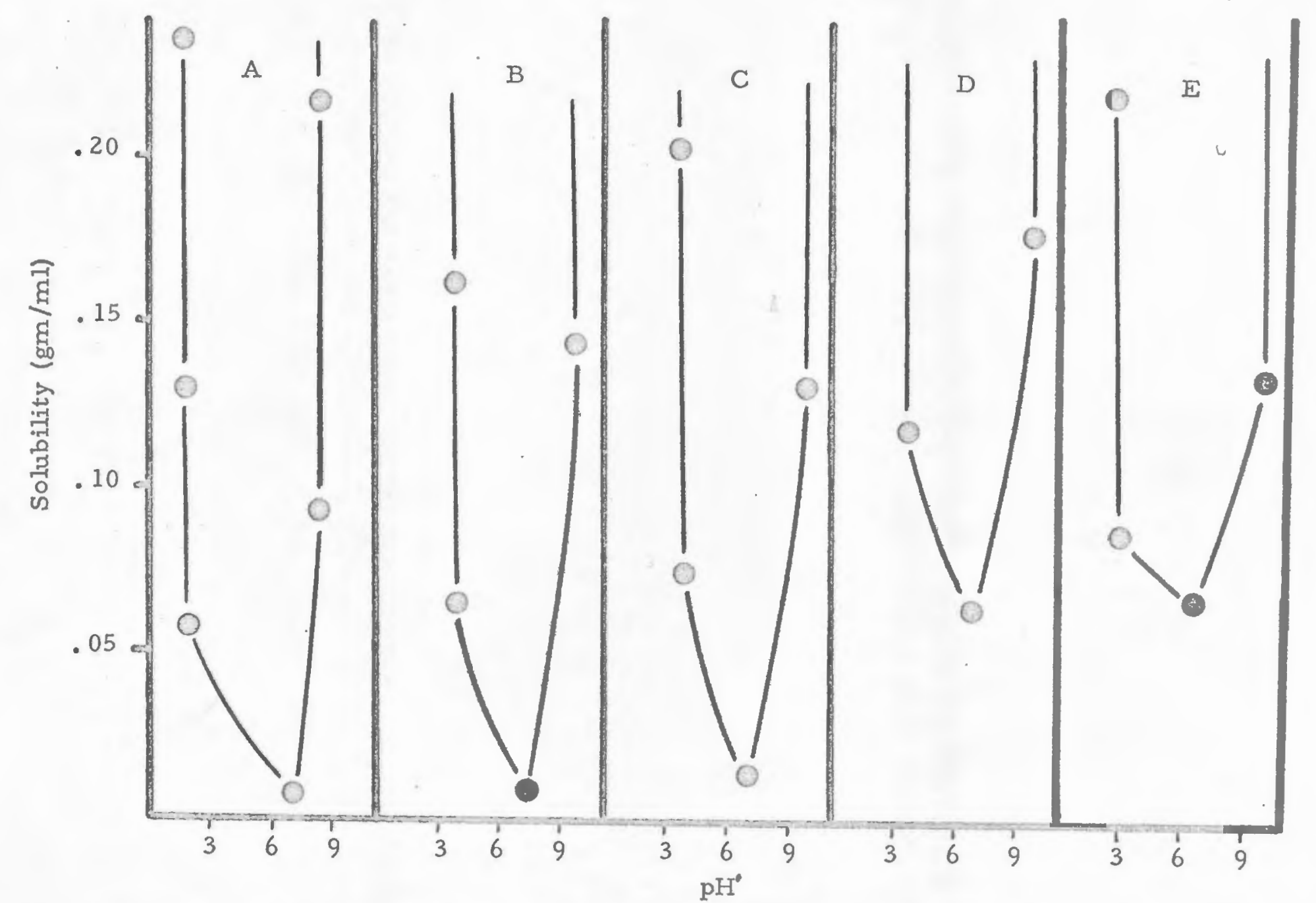

Figure 11. The Solubility of the Amino Acids in Pure Methanol as a Function of $\mathrm{pH}^{\text {: }}$

Column A - Glycine, Column B - L-Alanine, Column C - L-Valine, Column DL-Phenylalanine, Column E - DL-Aminooctanoic Acid。 


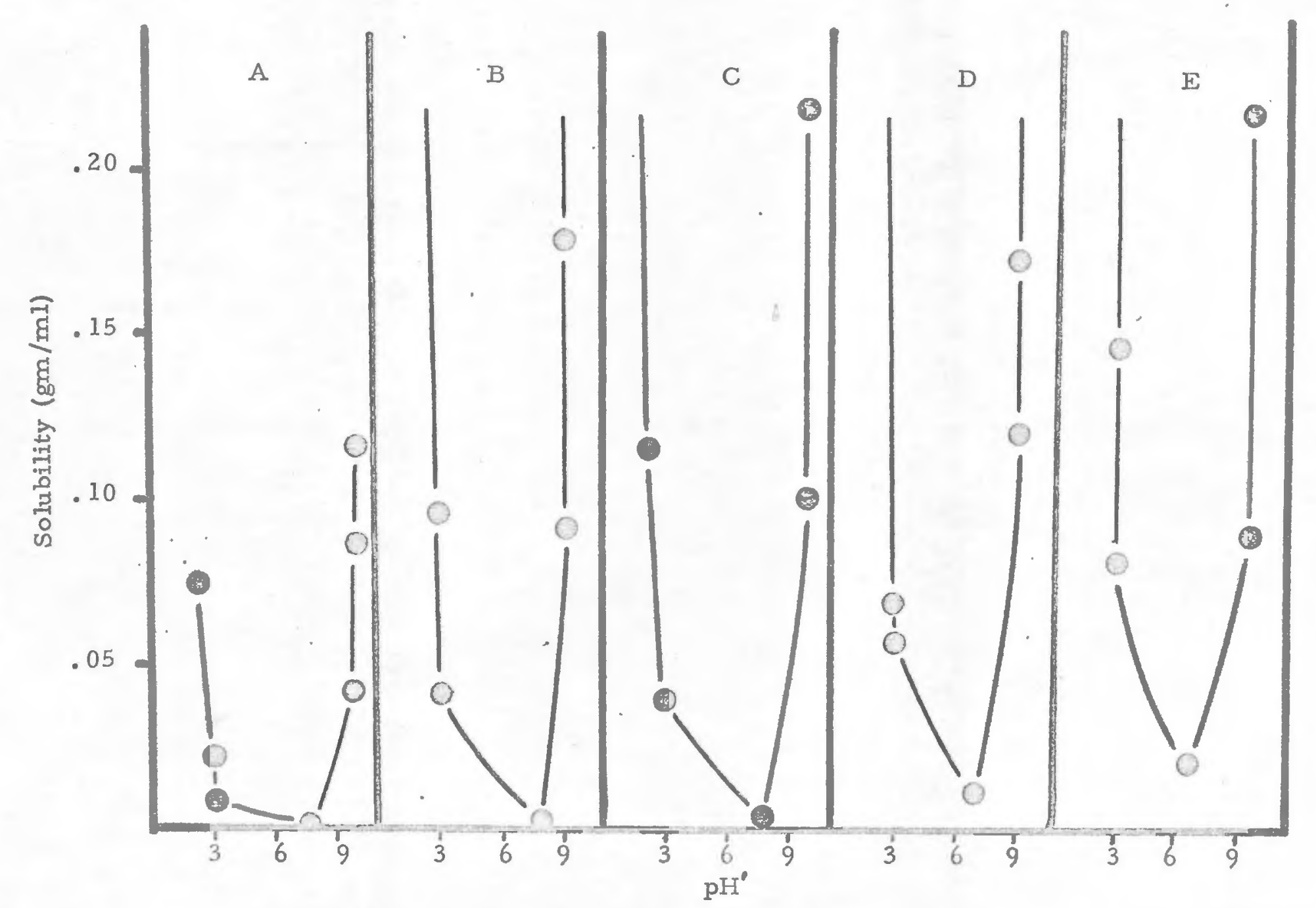

Figure 12. The Solubility of the Amino Acids in Pure Ethanol as a Function of pH: Column A - Glycine, Column B - L-Alanine, Column C - L-Valine, Column D. L-Phenylalanine, Column E - DL-Aminooctanoic Acid. 


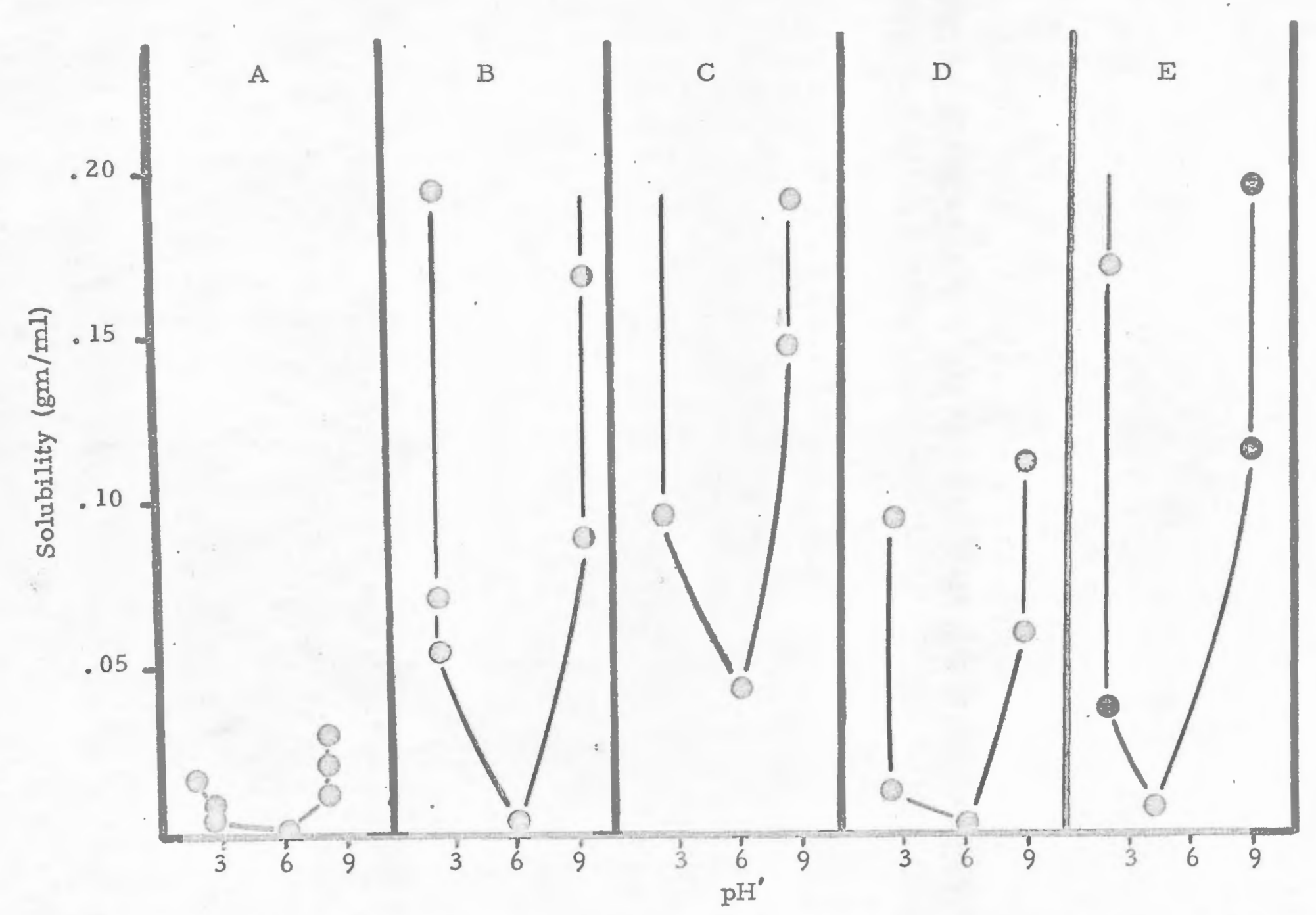

Figure 13. The Solubility of the Amino Acids in Pure n-Propanol as a Function of pH: Column A - Glycine, Column B - L-Alanine, Column C - L-Valine, Column DL-Phenylalanine, Column E - DL-Aminooctanoic Acid. 


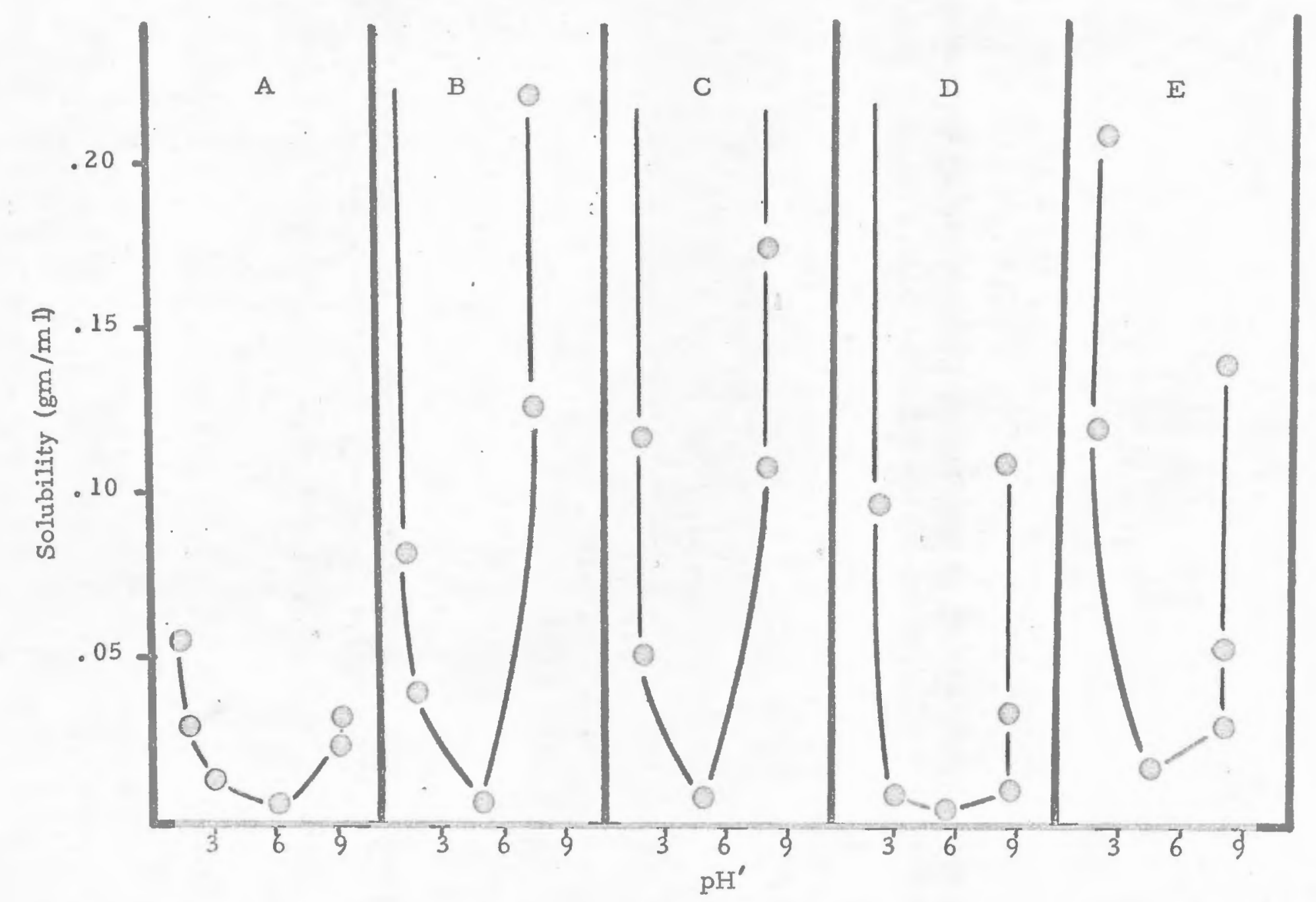

Figure 14. The Solubility of the Amino Acids in Pure Isopropanol as a Function of pH: Column A - Glycine, Column B - L-Alanine, Column C - L-Valine, Column DL-Phenylalanine, Column E - DL-Aminooctanoic Acid. 


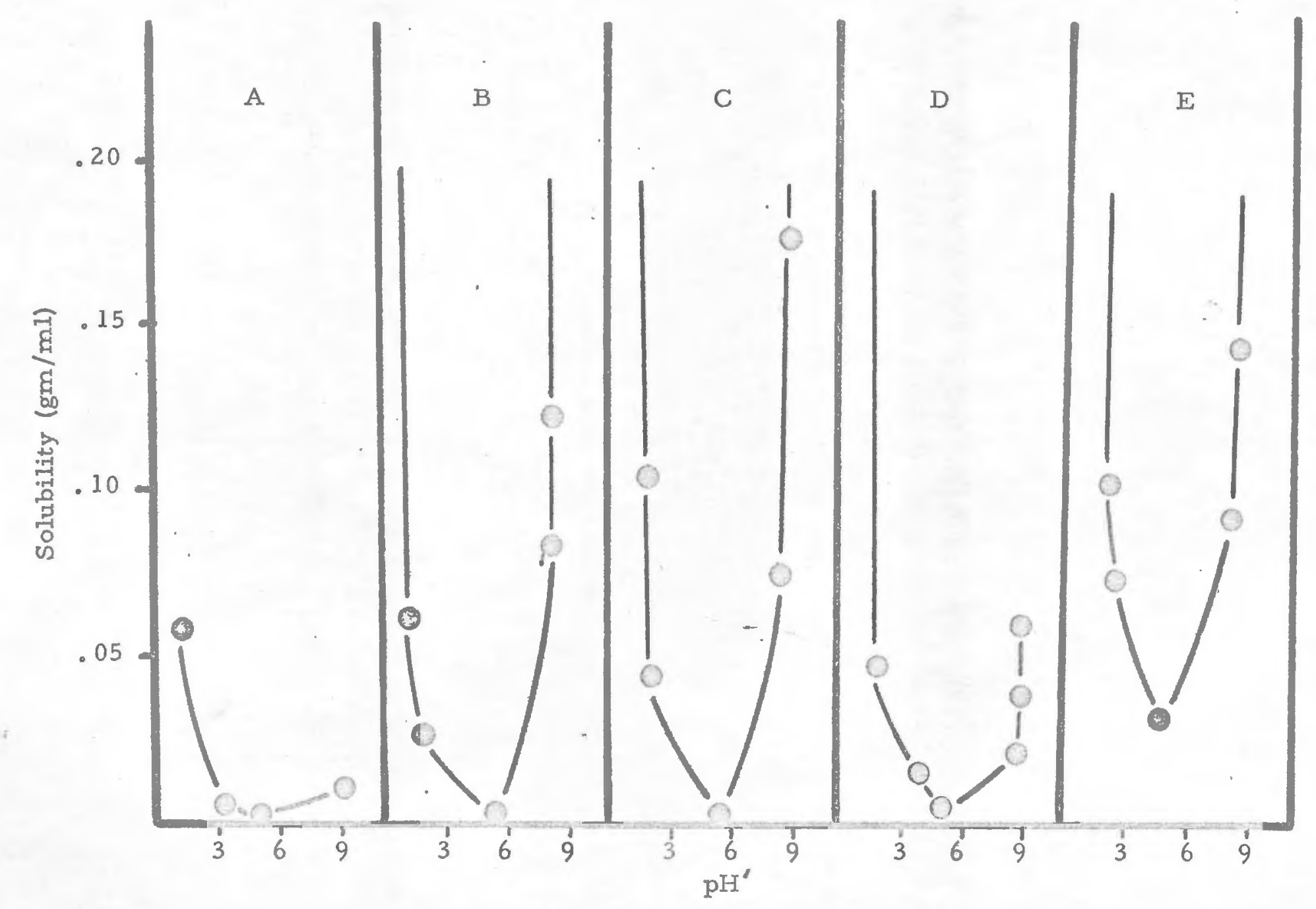

Figure 15. The Solubility of the Amino Acids in Pure Tertiary Butanol as a Function of pH: Column A - Glycine, Column B - L-Alanine, Column C - L-Valine, Column DL-Phenylalanine, Column E - DL-Aminooctanoic Acid. 


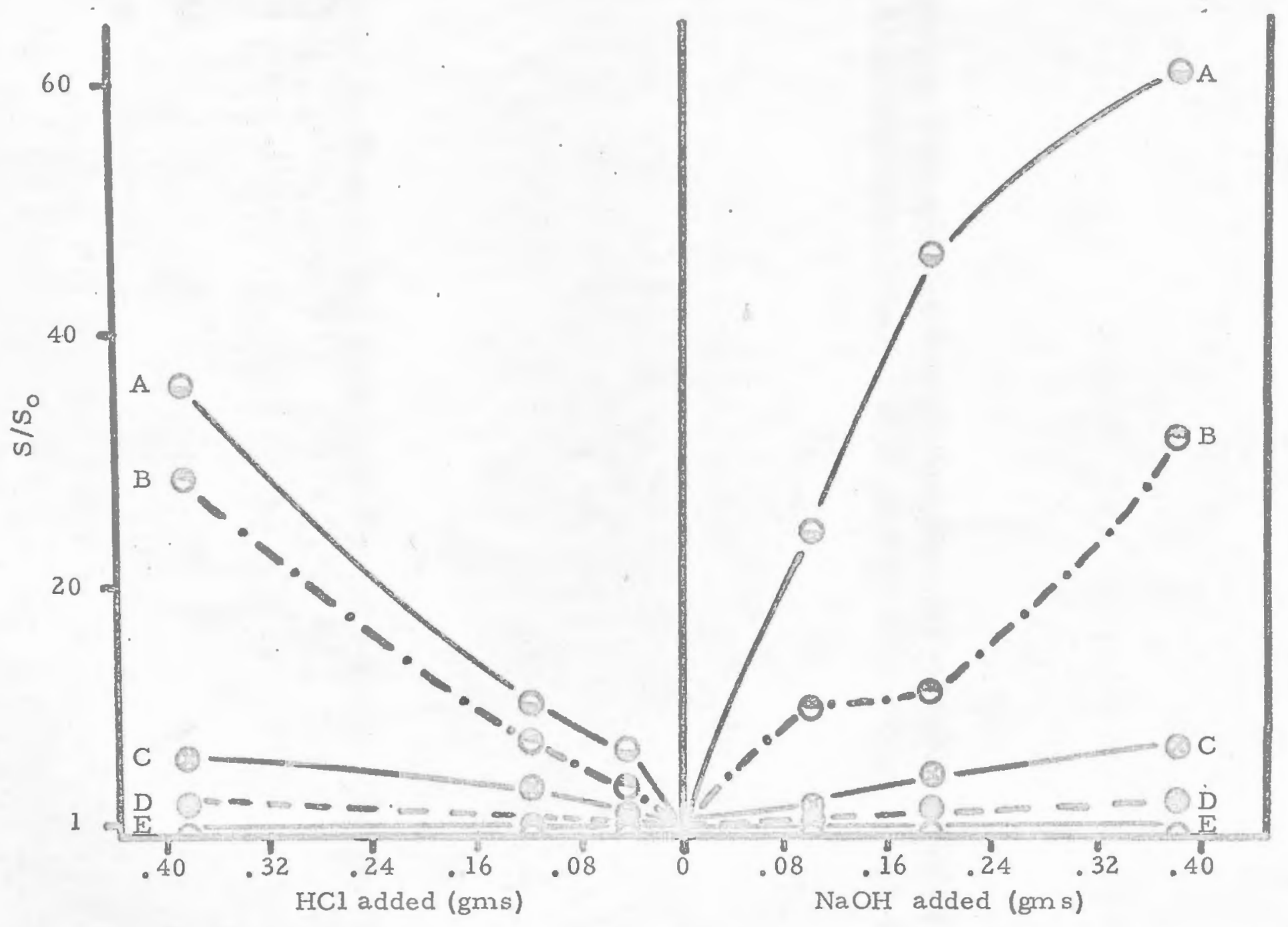

Figure 16. The Ratio of the Total Solubility (S) to the Solubility at the Neutral Point (S.) for Glycine as a Function of $\mathrm{HCl}$ and $\mathrm{NaOH}$ added in an Ethanol-Water System. Curve A-100\%, Curve B-90\%, Curve C-70\%, Curve D-50\%, Curve E-0,10,30\% $(v / v)$ of Ethanol 


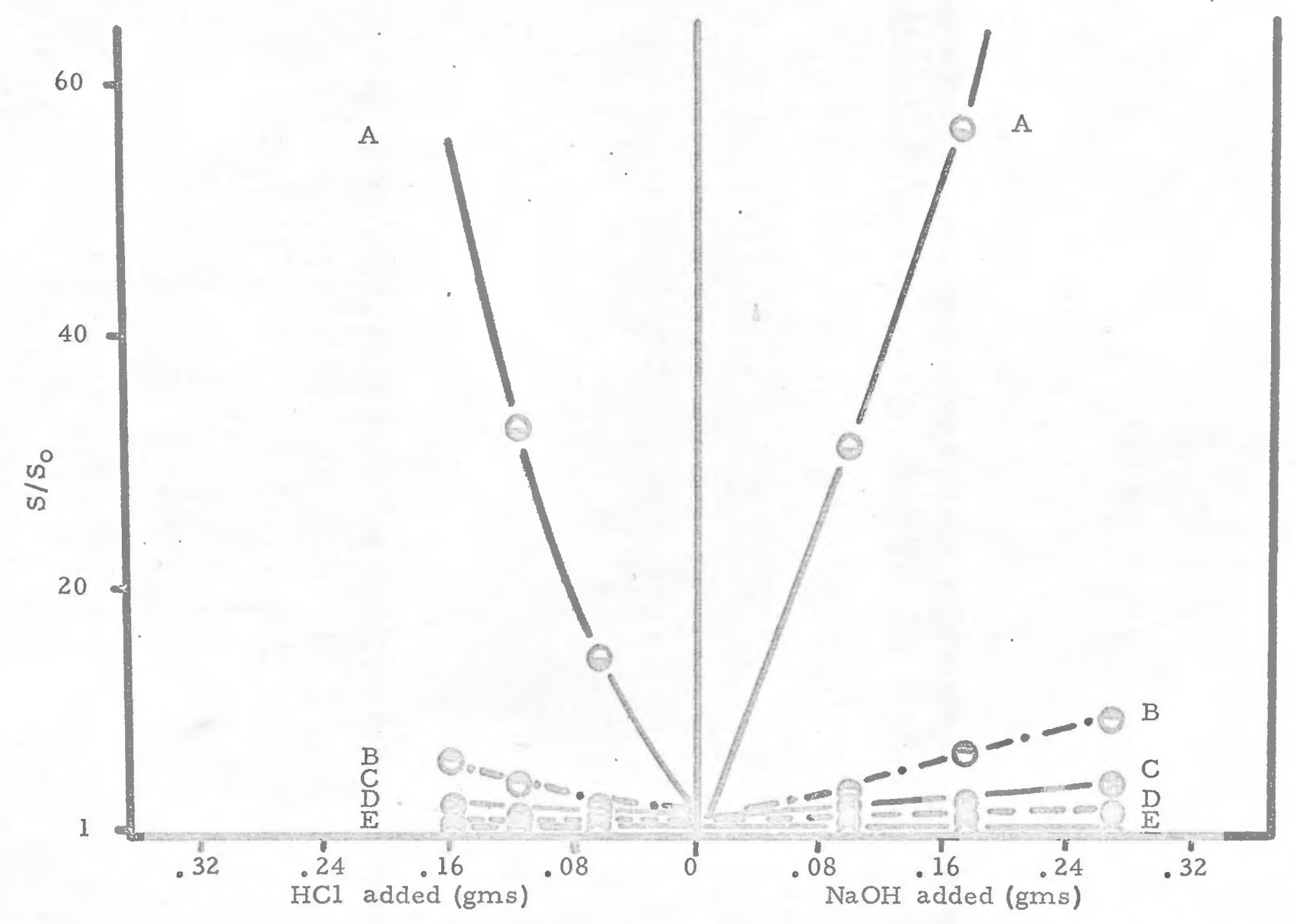

Figure 17. The Ratio of the Total Solubility (S) to the Solubility at the Neutral Point (So) for L-Alanine as a Function of $\mathrm{HCl}$ and $\mathrm{NaOH}$ added in an Ethanol-Water System. Curve A-100\%, Curve B-90\%, Curve C-70\%, Curve D-50\%, Curve E-0,10,30\% $(v / v)$ of Ethanol. 


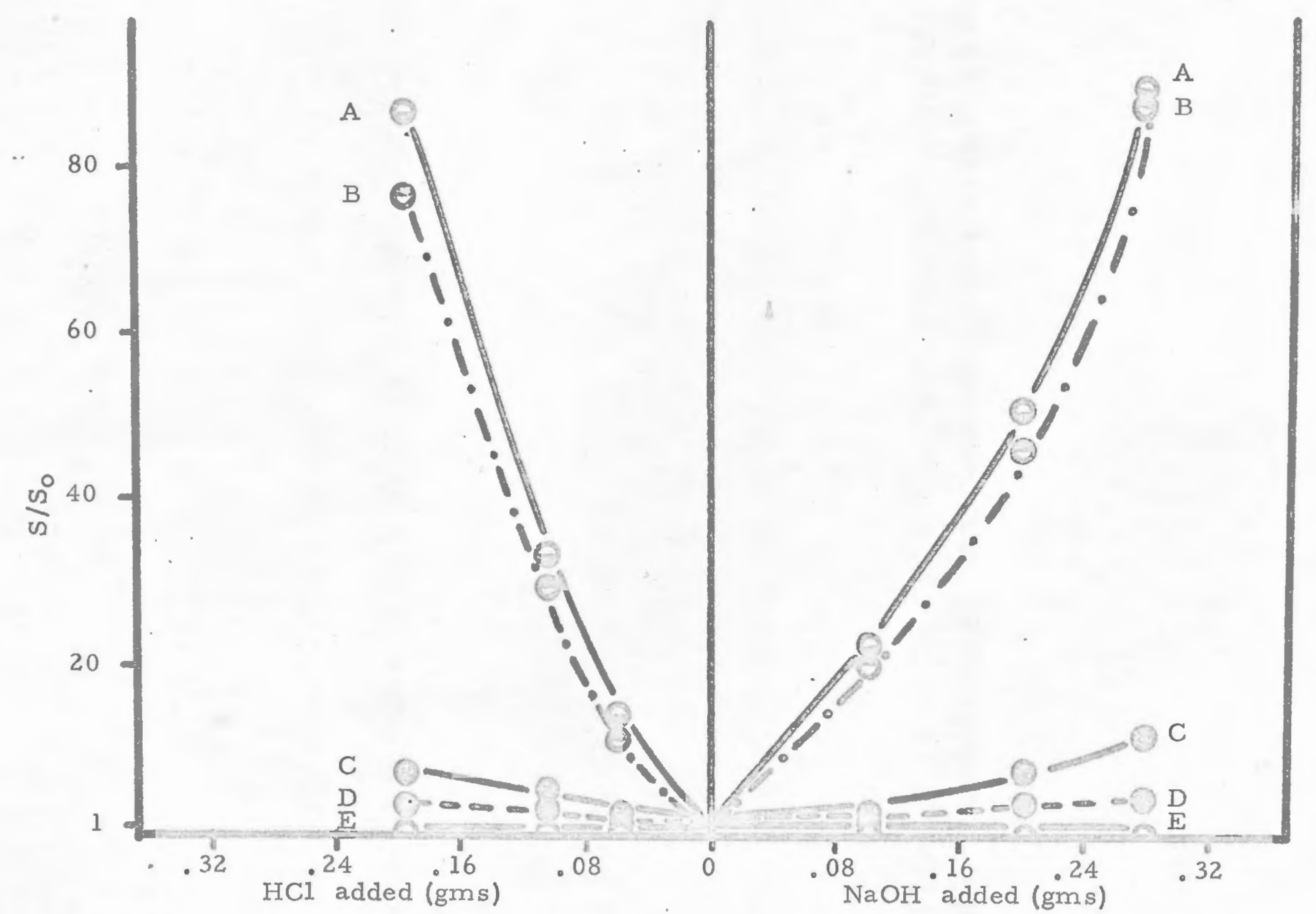

Figure 18. The Ratio of the Total Solubility (S) to the Solubility at the Neutral Point $\left(S_{0}\right)$ for $\mathrm{L}-\mathrm{Valine}$ as a Function of $\mathrm{HCl}$ and $\mathrm{NaOH}$ added in an Ethanol-Water System.

Curve A-100\%, Curve B- $90 \%$, Curve C-70\%, Curve D-50\%, Curve E-0,10,30\% $(v / v)$ of Ethanol. 


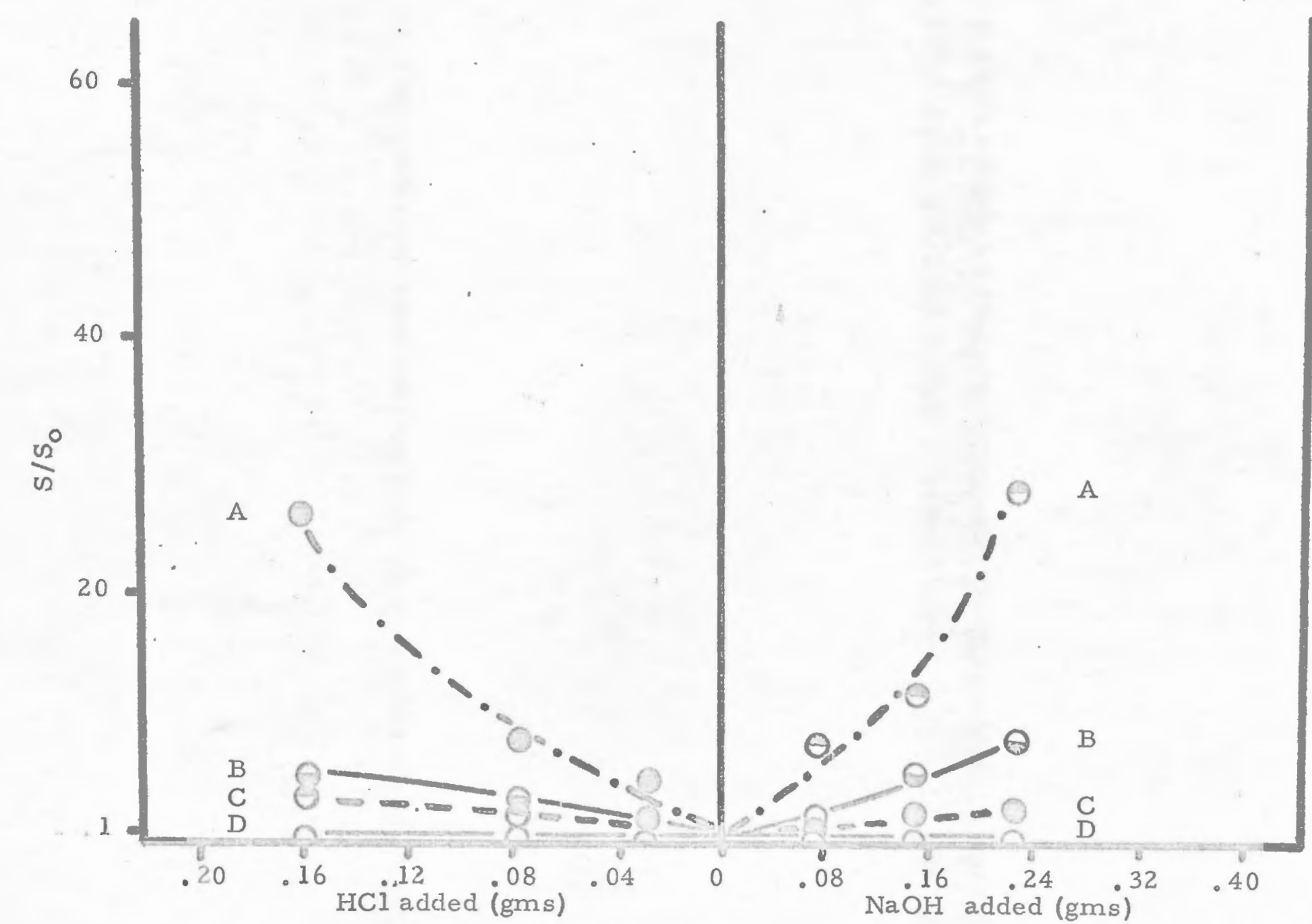

Figure 19. The Ratio of the Total Solubility (S) to the Solubility at the Neutral Point (So) for L-Phenylalanine as a Function of $\mathrm{HCl}$ and $\mathrm{NaOH}$ added in an Ethanol-Water System. Curve A-100\%, Curve B-70,90\%, Curve C-30,50\%, Curve D-0,10\%, (v/v) of Ethanol. 
The $50 \%$ and $70 \%(\mathrm{v} / \mathrm{v})$ begin to show a slight increase in salt formation as evidenced by an increase in the slope of the line. The $90 \%$ and $100 \%(\mathrm{v} / \mathrm{v})$ solutions of ethanol show a distinct increase in the efficiency of salt formation except in the case of L-phenylalanine which shows a distinct break only at 100\%. This increasing efficiency of salt formation can be correlated with mole fraction or essentially the number of molecules of water present as compared to the number of molecules of the semi-polar solvent. Note that up to $70 \%$ ethanol the number of water molecules is greater or equivalent to the number of ethanol molecules. (See Table 10) However, between $70 \%$ and $90 \%$ the ethanol molecules begin to outnumber the water molecules and this in turn corresponds to the increased efficiency of salt formation in the solvent systems. In a solvent system as the dielectric constant of the medium is reduced, the interionic forces become more important since they compose an increasingly greater portion of the attractive charge between oppositely charged ions. These ions of $\mathrm{Na}$ or $\mathrm{Cl}$ which are added separately to different solvent systems, as $\mathrm{HCl}$ or $\mathrm{NaOH}$, can be attracted to the dipolar ions in the form of cations or anions to form the amino acid salts or can form associations with the hydrogen or hydroxyl ions with which they were added. However, in considering the activity coefficients for pure $\mathrm{HCl}(38)$ and pure $\mathrm{NaOH}$ (39) solutions at the molar concentrations of acid or base which were added to the amino acids in the semi-polar solvents; it was found that at the highest concentration of 
acid or base added the activity coefficients were reported to be approximately 0.86 and 0.85 respectively. Therefore it would seem that at the low concentrations of acid or base added in solutions of low dielectric constant, the $\mathrm{Cl}^{-}$and $\mathrm{Na}^{+}$ions would provide the major attractive force for the predominately charged amino acids. This increased attraction as the polarity of the solvent system is reduced would seem to explain the greater efficiency of salt formation.

Further, the comparison of the ratio of $S$ to $S_{0}$ with the quantity of acid or base added seems to provide an indication of a reduction in the isoelectric band. Since by definition the species present within the isoelectric band are predominately dipolar and produce an invariant solubility, it would seem that an increase in total solubility could be attributed to salt formation. The increase in the $S / S_{0}$ ratio as the percent alcohol was increased would indicate a reduction in the isoelectric band as a function of decreasing polarity. This reduction was due to an increased affinity of the amino acids for the $\mathrm{Na}^{+}$ and $\mathrm{CI}^{-}$ions. 


\section{CONCLUSIONS}

1. The solubility behavior of the amino acids studied is a function of the constant effect of the $\alpha$-amino carboxylic acid portion of the molecule, and the independent interaction of the remaining portion of the molecule.

2. In the hydroalcoholic solvent systems studied, the solubility of glycine, L-alanine, L-valine, and L-phenylalanine is dominated by the $\alpha$-amino carboxylic portion of the molecule. Maximum solubility is shown in pure water with a reduction to very low solubility in the semi-polar solvents in the order of a second degree polynomial equation.

3. Each of the amino acids studied demonstrated an ability to differentiate between the hydroalcoholic solvents used throughout the concentration spectrum. A family of second degree polynomial curves could be generated from the solubility data as a function of percent $(v / v)$ of each alcohol. The quantitative order of solubility of each amino acid varied in the solvent systems studied. This would indicate that the structural differences in the alcohols produce slight changes in solubility of each amino acid, but that an overall similarity 
in the solubility profile will be seen. Further, structural differences in the non-polar portion of the amino acid molecules will produce different interactions with molecules of the solvent systems and produce an order of solubility which is characteristic of the specific amino acid.

4. For those amino acids studied in aqueous solvent systems, a band of minimum solubility is found from a pH above and below the isoelectric point. A distinct increase in total solubility is seen as the $\mathrm{pH}$ exceeds the limits of this isoelectric band.

5. In aqueous systems, the increase in total solubility of those amino acids studied is directly proportional to the moles of acid or base added.

Total solubility $=($ slope $)($ moles of acid or base added $)+$ initial solubility of the amino acid.

The slope which represents the increase in total solubility as a function of acid or base added shows an increase as the non-polar to polararatio of the amino acids increases. This would indicate that as the non-polar portion of the amino acid molecule increases, the anion or cation species is more readily available for salt formation.

6. The total solubility of the amino acids studied at various $\mathrm{pH}^{\prime} \mathrm{s}$ in aqueous solutions is the sum of the original zwitterion 
solubility plus the salt formed by acid or.base addition. Under the experimental conditions observed, the amino acids studied form the single salts.

7. In the hydroalcoholic solvent systems studied, the amino acids show a minimum solubility at a $\mathrm{pH}^{2}$ corresponding to the isoelectric point. However, the isoelectric band seen in aqueous systems was not seen.

8. As the percent of alcohol increased in those solvent systems studied, similar increments of acid or base added to the system produced a proportionally greater increase in the magnitude of the total solubility of the amino acids. This was attributed possibly to an increase in the importance of the charged species as the polarity of the solvent system was decreased as well as the increased affinity of the amino acids for the $\mathrm{Na}^{+}$and $\mathrm{Cl}^{-}$ions present. 


\section{REFERENCES}

(1) Cohn, E. J., and Edsall, J. T., Proteins, Amino Acids, and Peptides, (Reinhold, New York, 1943), p. 78.

(2) Edsall, J. T., and Blanchard, M. H., J. Am. Chem. Soc., 55, 2338, (1933).

(3) Ebert, L., Z. Physik Chem., 121, 385, (1926).

(4) Fox, S. W., and Foster, J. F., Protein Chemistry, (J. Wiley \& Sons, New York, 1957), pp. 29-30.

(5) Martin, A. N., Physical Pharmacy, (Lea \& Febiger, Philadelphia, 1960), p. 233.

(6) Cohn, E. J., and Edsall, J. T., 오. cit., p. 91.

(7) Fox, S. W., and Foster, J. F., ㅇp. cit., p. 38.

(8) Edsall, J. T., and Blanchard, M. H., loc. cit., p. 2352.

(9) Greenstein, J. P., and Winitz, M., Chemistry of the Amino Acids, vol. 1, (J. Wiley \& Sons, New York, 1961) pp. 549-647.

(10) Dunn, M. S., Ross, F. J., and Reid, L. S., J. Biol. Chem., 103, 579, (1933).

(11) Vickery, H. B., J. Biol. Chem., 169, 237, (1947).

(12) Edsall, J. T., J. Chem. Phys., 4, 1, (1936).

(13) Edsall, J. T., J. Chem. Phys., 5, 222, (1937). 
(14) Edsall, J. T., The Chemistry of Amino Acids and Proteins (Charles C. Thomas, Springfield, 1944).

(15) Cohn, E. J., McMeekin, T. L., Edsall, J. T., and Blanchard, M. H., J. Am. Chem. Soc., 56, 784, (1934).

(16) Wyman, J., Jr., Chem. Revs., 19, 213, (1936).

(17) Weast, R. C., ed., Handbook of Chemistry and Physics, 47 th ed., (Chemical Rubber Co., Cleveland, Ohio, 1966), p. C-705.

(18) Cohn, E. J., and Edsall, J. T., op. cit., pp. 199-201.

(19) Cohn, E. J., and Edsall, J. T., op. cit., pp. 205-211.

(20) Cohn, E. J., McMeekin, T. L., Edsall, J. T., and Weare, J., J. Am. Chem. Soc., 56, 2270, (1934).

(21) McMeekin, T. L., Cohn, E. J., and Weare, J., J. Am. Chem. Soc., 57, 626, (1935)

(22) Edsall, J. T., and Blanchard, M. H., loc. cit, p. 2337.

(23) Ibid., 55, 2352 (1933).

(24) Ibid., 55, 2347, (1933).

(25) Cohn, E. J., Chem. Revs., 19, 241, (1936).

(26) Dunn, M. S., and Ross, F. J., J. Biol. Chem., 125, 309 (1938).

(27) Nozaki, Y., and Tanford, C., I. Biol. Chem., 238, 4078, (1963).

(28) System/360 Scientific Subroutine Package (360A-CM-03X) Version III Programmers Manuel, (White Plains, IBM Corp., 1968), pp.408.

(29) Snedcor, G. W., and Cochran, W. G., Statistical Methods, 6th ed. , (Iowa State University Press, Ames, Iowa, 1967), pp. 460-4.

(30) Edsall, J. T., and Blanchard, M. H., loc. cit., p. 2338. 
(31) Ibid., 55, 2339, (1933).

(32) Cohn, E. J., and Edsall, J. T., op. cit., p. 90.

(33) Ibid., p. 91.

(34) Schmidt, C. L. A., ed., Chemistry of Amino Acids and Proteins, (C. C. Thomas, Springfield, 1938) Chap. 11.

(35) Michaelis, L., Hydrogen Ion Concentration, (Williams and Wilkins Co., Baltimore, 1926).

(36) Greenstein, J. P., and Winitz, M., Chemistry of the Amino Acids, vol. I, (J. Wiley \& Sons, New York, 196 I) pp. $\overline{647-5}$.

(37) Cohn, E. J., and Edsall, J. T., op. cit., pp. 84-86.

(38) Scatchard, G. J., J. Am. Chem. Soc., 47, 696, (1925).

(39) Lewis, G. N., and Randall, M., Thermodynamics and Free Energy of Chemical Substances, (McGraw Hill Book Co., New York, 1923) p. 302 . 


\section{APPENDIX}

I. Program Fitting a Set of Data to a Polynomial Equation

A successive series of polynomial equations are calculated from a set of data consisting of two variables, $\mathrm{X}$ and $\mathrm{Y}$. The $\mathrm{Y}$ intercept and the coefficients for each degree of $\mathrm{X}$ is given. A standard analysis of variance table is displayed for each degree of the polynomial calculated. The sum of the squares of the deviation about the regression for the polynomial equation if compared with that of the preceeding equation. The program is terminated when no improvement in the fit of the equation is shown.. A table of residuals is calculated to show the difference between the input data and the data computed from the final polynomial equation. A graph is produced showing the calculated and observed values of the dependent variable as a function of the independent variable for the highest polynomial equation computed.

The actual program written in Fortran IV computer language as well as related theoretical references may be found in references $(28, \cdots 29)$. 
II. Program Computing Least Squares of a First Degree

Equation with Correlation Coefficient.

DIMENSION X(20), Y(20), XD(20), YD(20), XDS(20), YDS(20), $X Y(20), A L F(15)$

$\operatorname{READ}(5,1) A L F$

1 FORMAT(15A4)

$\operatorname{READ}(5,2) \mathrm{N}$

2 FORMAT(I2)

DO $4 \mathrm{I}=1, \mathrm{~N}$

$\operatorname{READ}(5,3) X(I), Y(I)$

3 FORMAT(2F6.4)

4 CONTINUE

$\mathrm{XSM}=0$

$Y S M=0$

DO $5 \mathrm{I}=1, \mathrm{~N}$

$\mathrm{XSM}=\mathrm{XSM}+\mathrm{X}(\mathrm{I})$

$Y S M=Y S M+Y(I)$

5 CONTINUE

$\mathrm{XA}=\mathrm{XSM} / \mathrm{N} \bullet$

$Y A=Y S M / N$

$X Y S=0$

$\mathrm{XDSS}=0$

$Y$ DSS $=0$

DO $6 \mathrm{I}=1, \mathrm{~N}$

$\mathrm{XD}(\mathrm{I})=\mathrm{X}(\mathrm{I})-\mathrm{XA}$

$Y D(I)=Y(I)-Y A$

$X D S(I)=X D(I) * 2$

$Y D S(I)=Y D(I) * 2$

$X Y(I)=X D(\dot{I}) * Y D(I)$

$X Y S=X Y S+X Y(I)$

$X D S S=X D S S+X D S(I)$

$Y D S S=Y D S S+Y D S(I)$

6 CONTINUE

SLOPE $=X Y S / X D S S$

$\mathrm{R}=\mathrm{XYS} / \mathrm{SQR} \mathrm{T}$ (XDSS*YDSS)

WRITE $(6,10)$

10 FORMAT(///, T20, 'CORRELATION COEFFICIENT OF

AMINO ACID VS. ACID OR BASE ADDED')

WRITE $(6,11) A L F$

11 FORMAT $(/ /, \mathrm{T} 25,15 \mathrm{~A} 4)$

WRITE $(6,12) R$, SLOPE

12 FORMAT(//, T35, 'R = ', T45, F6.4, //, T35, 'SLOPE = ', 


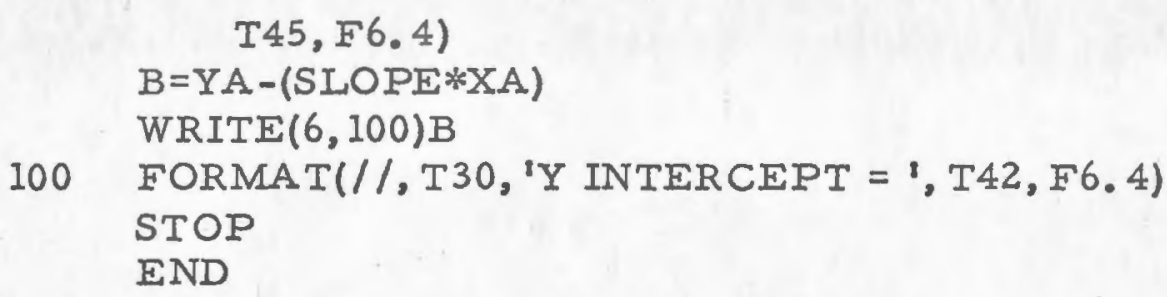

